\title{
Effect of Longitudinal-External-Fins on Fluid Flow Characteristics for Wing-Shaped Tubes Bundle in Crossflow
}

\author{
Sayed Ahmed E. Sayed Ahmed, Osama M. Mesalhy, and Mohamed A. Abdelatief \\ Mechanical Power Engineering Department, Faculty of Engineering, Zagazig University, Zagazig 44519, Egypt \\ Correspondence should be addressed to Mohamed A. Abdelatief; eng_aboatia@yahoo.com
}

Received 4 July 2015; Revised 15 September 2015; Accepted 16 September 2015

Academic Editor: Shou-Shing Hsieh

Copyright (C) 2015 Sayed Ahmed E. Sayed Ahmed et al. This is an open access article distributed under the Creative Commons Attribution License, which permits unrestricted use, distribution, and reproduction in any medium, provided the original work is properly cited.

\begin{abstract}
A numerical study is conducted to clarify fluid-flow characteristics, pressure drop coefficient $\left(P_{\mathrm{dc}}\right)$, and the average skin friction coefficient $\left(C_{f, m}\right)$ for wing-shaped-tubes bundle with longitudinal fins at downstream side of the tube using the commercial CFD FLUENT software package. The air-side $\operatorname{Re}_{a}$ ranges from 1800 to 9700 . The tubes are employed with various fin heights $\left(h_{f}\right)$ and fin thicknesses $(\delta)$ such as $2 \mathrm{~mm} \leq h_{f} \leq 12 \mathrm{~mm}$ and $1.5 \mathrm{~mm} \leq \delta \leq 3.5 \mathrm{~mm}$ at the considered $\operatorname{Re}_{a}$ range. Results indicate that $\Delta P_{a}$ increases with $\operatorname{Re}_{a}$ for all $h_{f}$. $P_{\mathrm{dc}}$ decreases with $\operatorname{Re}_{a}$ for all $h_{f}$ values for $1800 \leq \operatorname{Re}_{a} \leq 4200$ and then increases for $4200 \leq \operatorname{Re}_{a} \leq$ 10000. Lowest values of $\Delta P_{a}, P_{\mathrm{dc}}$, and pumping power (PP) occurred at $h_{f}=6 \mathrm{~mm}$. Values of $P_{\mathrm{dc}}$ for $h_{f}=6 \mathrm{~mm}$ are lower than those of NOF and $h_{f}=2 \mathrm{~mm}$ by about $73 \%$ and $32 \%$, respectively, at $\operatorname{Re}_{a}=4000 . C_{f, m}$ decreases with $\operatorname{Re}_{a} . \delta$ has negligible effect on $C_{f, m}$. $\Delta P_{a}$ increases for $1.5 \mathrm{~mm} \leq \delta \leq 2.5 \mathrm{~mm}$ while $\Delta P_{a}$ decreases with $2.5 \mathrm{~mm}<\delta \leq 3.5 \mathrm{~mm}$ for the considered $\operatorname{Re}_{a}$ range except for $\operatorname{Re}_{a}=1850$.
\end{abstract}

\section{Introduction}

Finned tube heat exchangers are extensively employed in chemical engineering, refrigeration, and HVAC applications. The dominant thermal resistance is usually on the air side in practical applications, and therefore the use of finned surfaces on the air side is very common to effectively improve the overall thermal performance of heat exchangers. Depending on the application, various fin patterns such as plate, louver, convex louver, and wavy fin are used.

There is, of course, an associated increase in $\Delta P_{a}$ due to the increase of friction and the drag contribution from the finite thickness of the interrupted fins. The typical tube geometries used in most of heat exchangers are circular and elliptical ones. A detailed survey on tube heat exchangers with different types of fin configurations is presented as follows.

Chen et al. [1] applied the inverse scheme of the finite difference method in conjunction with the least-squares scheme and experimental temperature data to estimate the air flow and heat transfer characteristics on vertical plate finned tubes heat exchanger in forced convection for various air speed $\left(V_{a}\right)$ and fin spacing $(S)$. Results showed that the fin efficiency $\left(\eta_{f}\right)$ values decreased with increasing $S$ and $V_{a}$ values. A combined numerical and experimental study of plate finned tubes heat exchangers was examined by Jang et al. [2]. They presented detailed numerical results of $\Delta P_{a}$ and $h_{a}$, but experimental results were not enough. A systematic study on heat and friction characteristics of plate finned tubes heat exchangers was experimentally investigated by Wang et al. [3]. Results are limited to the cases with relatively large fin pitch heat exchangers.

Khudheyer and Mahmoud [4] carried out a numerical study on finned tubes heat exchanger to make CFD simulations and validated the results against experimental data. Ten different inlet $\mathrm{Re}_{a}$ 's ranging from 330 to 7000 were simulated for turbulence models of laminar, $k$-epsilon, and SST $k$-omega. Reasonable agreement was found between the simulated and experimental data.

Three-dimensional CFD simulations were carried out to investigate heat transfer and fluid flow characteristics of three-row plain finned tubes heat exchangers using FLUENT software by Ghori and Kirar [5]. Pressure drop characteristics of the heat exchanger were investigated for Re ranging from 330 to 7000 . Fluid flow was simulated and results compared 
for laminar flow model, turbulent flow models $k$ - $\varepsilon$, and SST $k$ omega, with steady-state solvers to determine pressure drop $\Delta P$, and temperature fields. Model validation was carried out by comparing simulated values of friction factor $(f)$ with experimental results by Wang et al. [3]. Reasonable agreement between simulated and experimental data was found, thus proving that the FLUENT software is sufficient for simulating the flow fields in finned tubes heat exchangers.

Yan and Sheen [6] have carried out an experiment to investigate the heat transfer and pressure drop characteristics of finned tubes heat exchangers with plate, wavy, and louvered finned tubes. They found that, at the same $\operatorname{Re}_{a}$, louvered finned heat exchanger shows larger values of $f$ compared with those for plate finned tubes one. Wolf et al. [7] studied the air flow and heat transfer performance of a wavy finned tubes heat exchanger by numerical and experimental methods. The air side pressure drop characteristics were successfully modeled using the CFD software FLUENT. The numerical results were validated with the experimental ones and the deviation was within $8 \%$. Tang et al. [8] carried out an experimental and numerical study on the air side performance of finned tubes heat exchangers with various fin configurations, such as crimped spiral, plain, and slit finned tube heat exchanger. It was found that the heat exchanger with the crimped spiral fin has better performance than those for the other configurations. Also, it is found that heat exchanger with slit fins offers the best performance at higher $\mathrm{Re}_{a}$.

Leu et al. [9] conducted a numerical simulation for louvered fin and tube heat exchangers having circular and oval tube configurations. The effects of the geometrical parameters such as louver angle $(\theta)$, louver pitches $\left(L_{p}\right)$, and louver length $\left(L_{l}\right)$ were discussed. T'Joen et al. [10] worked on the interaction between the flow behavior (flow deflection and transition to unsteady flow) and the thermohydraulic performance of heat exchanger with an inclined louvered fin design. In this experiment, the impacts of fin pitch $\left(F_{p}\right)$, $(\theta)$, and $\operatorname{Re}_{a}$ were discussed in detail. Li and Wang [11] conducted an experimental study on the air side heat transfer and pressure drop characteristics of brazed aluminum heat exchangers, with multiregion louver fins and flat tubes. They found that $\Delta P_{a}$ tends to decrease with increasing $\operatorname{Re}_{a}$ and increase with the number of louvers.

Heat transfer and pressure drop characteristics for longitudinally finned tubes banks had been carried out by Sparrow and Kang [12]. The investigated geometrical parameters included the placement of the fins at the tube frontal side, at the rear, and at both. Results indicated that finned tube actually reduced the pressure drop relative to the corresponding unfinned tube. For the same pressure drop, finning yields significantly greater enhancements. At fixed mass flow, greater enhancements were attained with increased-diameter unfinned tubes, but at a high penalty in pressure drop and pumping power.

An experimental investigation had been conducted by Ibrahim and Moawed [13] to clarify heat transfer characteristics and entropy generation for individual elliptical tubes with LF. The investigated geometrical parameters included the placement of the fins at the front of the tube, at the rear of the tube, and at both. The air $\mathrm{Re}_{a}$ ranged from about
$4.7 \times 10^{3}$ to $3.96 \times 10^{4}$. The analysis of the entropy generation is based on the principle of minimizing the rate of total entropy generation that includes the generation of entropy due to heat transfer and friction losses. Results indicated that the fin position on the elliptical tube has an effect on the results of $f$ and irreversibility ratio $(\Phi)$. The correlations of average $f$ and $\Phi$ with $\operatorname{Re}_{a}$ were presented.

Torabi and Zhang [14] studied, analytically, the temperature distribution within convective-radiative straight fins with simultaneous variation of $k, h_{a}$, surface emissivity $(B)$, and internal heat generation with temperature. They assumed nonzero convective and radiative sink temperatures for their analysis. Rectangular, triangular, convex, and exponential LF were considered. Calculations are carried out using the wellknown, approximate analytical differential transformation method (DTM). From illustrative data, in this paper, one could find that fin with the rectangular profile has the highest $\eta_{f}$ comparing to the other three profiles. So, this paper showed the validity and great potential of the DTM for nonlinear problems in science and engineering applications.

There are few reports of implementation of longitudinal finned tubes heat exchanger (LFTH) for wing-shaped tubes. Notably, there are no reports on LFTH enhancement for multirow wing-shaped tubes heat exchangers. Therefore, the aim of the present study is to numerically investigate, by the aid of commercial code FLUENT version 6.3.26, the air flow, skin friction characteristics, and pressure contours through a wing-shaped tubes bundle in staggered arrangement with the placement of various longitudinal fins with different $h_{f}$ and $\delta$ at the downstream side of the tube. $h_{f}$ and $\delta$ are $2 \mathrm{~mm} \leq$ $h_{f} \leq 12 \mathrm{~mm}$ and $1.5 \mathrm{~mm} \leq \delta \leq 3.5 \mathrm{~mm}$ for the considered $\mathrm{Re}_{a}$ range.

\section{Description of the Computational Model}

The numerical model is used to study the hydrodynamic and thermal performance of a staggered wing-shaped tubes bundle with LF mounted at the rear side of the tubes. The computational model considered, in the present work, is a simple design of air to water heat exchanger. The heat exchanger domain consists of three connected rectangular duct sections, entrance, tube bundle, and exit, as shown in Figure 1. The entrance section dimensions are $305 \mathrm{~mm}$, $305 \mathrm{~mm}$, and $320 \mathrm{~mm}$ as height, width, and length, respectively. The exit section is similar to the entrance one. The tube bundle section is fixed between the two above-mentioned sections.

Schematic plane of the numerical domain for the crossflow over the tube bundle, shown in Figure 2, consists of 22 wing-shaped tubes, which are distributed through three successive rows in addition to four half dummy ones. The cross-sectional dimensions of wing-shaped tube, drawn from $1 \mathrm{~mm}$ thick, $22.5 \mathrm{~mm}$ outer diameter circular copper tube with $305 \mathrm{~mm}$ length, are shown in Figure 3. LF of copper sheet having a width of $305 \mathrm{~mm}$ and varied $h_{f}$ and $\delta$ such as $2 \mathrm{~mm} \leq$ $h_{f} \leq 12 \mathrm{~mm}$ and $1.5 \mathrm{~mm} \leq \delta \leq 3.5 \mathrm{~mm}$ are welded on the downstream side of the tube surface. Longitudinal $S_{L}$ and transverse $S_{T}$ tube pitches of $37 \mathrm{~mm}$ were kept constant. Hot air is forced to flow over the external cooled surface of the 


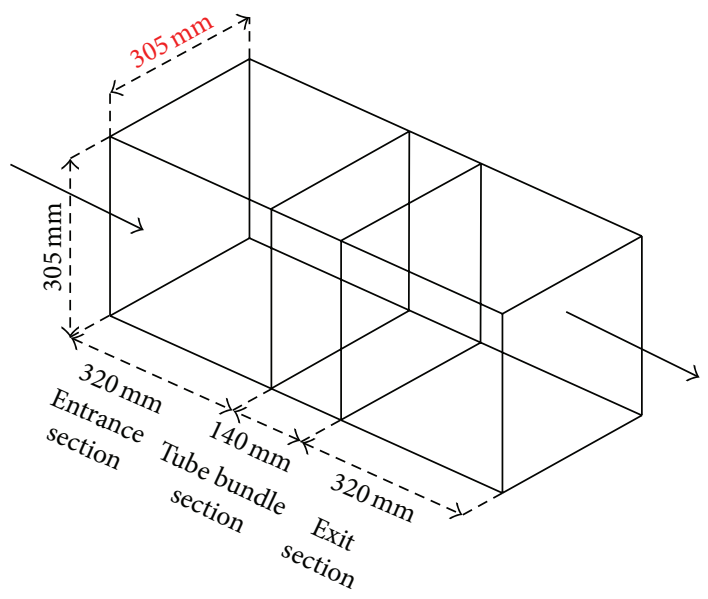

FIgURE 1: Heat exchanger domain.

tubes with different $\operatorname{Re}_{a}$. Flowing air velocity $\left(V_{\mathrm{ai}}\right)$ is varied from 1.33 to $7 \mathrm{~m} / \mathrm{s}$, yielding $\mathrm{Re}_{a}$ ranging from $1.8 \times 10^{3}$ to $9.7 \times$ $10^{3}$. Tubes surface temperature is kept constant.

\section{Numerical Investigation}

3.1. Problem Description and Boundary Conditions. Since the tube length is much greater than its equivalent diameter, the flow across the tube bundle is considered two-dimensional flow one. The geometry of the numerical model including the boundary conditions is shown in Figure 2. The numerical solution is carried out by solving the governing equations of mass, momentum, and energy under the following assumptions; the flow is incompressible, steady, and turbulent. The fluid properties are constant; also, the effects of buoyancy forces and radiation are neglected. Based on these assumptions the governing equations can be set as

$$
\begin{gathered}
\frac{\partial}{\partial x_{i}}\left(\rho V_{i}\right)=0.0 \\
\frac{\partial}{\partial x_{j}}\left(\rho V_{i} V_{j}\right)=-\frac{\partial p}{\partial x_{i}}+\frac{\partial \tau_{i j}}{\partial x_{j}} \\
\frac{\partial}{\partial x_{i}}\left[V_{i}(\rho E+p)\right]=\frac{\partial}{\partial x_{i}}\left(k \frac{\partial T}{\partial x_{i}}\right),
\end{gathered}
$$

where $i$ is a tensor indicating 1 and 2, $\tau_{i j}$ is the viscous stress tensor, and $k$ is the fluid effective thermal conductivity.

Commercial CFD software FLUENT 6.3.26 is used to solve the governing equations. RNG $k-\varepsilon$ turbulence model is used to simulate the flow fluctuations because it is reported to be more responsive to the effects of flow strain rate, which significantly improves the accuracy for rapidly strained flows, such as the case in reactive swirling flows. Also the RNG $k-\varepsilon$ model shows better performance than the standard $k-\varepsilon$ model in the prediction of heat transfer as examined by $\mathrm{Hu}$ and Sun [15]. The RNG $k-\varepsilon$ model has shown an excellent agreement between numerical and experimental results for an isothermal flow over backward facing step (Yakhot et al.)
[16]. The near wall region is treated using the enhanced wall method, which is capable of predicting the flow separation and recirculation behind bluff bodies, FLUENT [17].

3.2. Mesh Generation and Discretization. The geometry and mesh of the computational model described in the previous section are generated separately using GAMBIT 2.4.6. Quad/Map, Tri/Pave, and boundary layer meshing scheme is used in the present study with refining the mesh near walls and beside sharp edges.

Figure 4 shows the configuration of the computational mesh. Over the computational grid, the conservation equations as well as the turbulence equations are discretized using the second- order upwind scheme. The velocity pressure coupling is solved using SIMPLE algorism. The solution is considered converged when the scaled residual of the energy equation reaches $10^{-7}$ and the scaled residuals of other equations reach $10^{-4}$.

To test the dependence of the numerical results on the grid density, calculations are undertaken with different mesh densities in the $x$ and $y$ directions as recommended by FLUENT [17]. The first grid points adjacent to the walls were kept at $y^{+}$values between 1 and 5 . The grid sensitivity analysis is carried out, mainly, to obtain grid independent temperature distributions. The computational results of $h_{a}$ for the tube bundle are varied to give about $2.1 \%$ deviation when the number of grids ranges from 250,000 to 420,000 . On the other hand, when the grid size ranges from 300,000 to 420,000 , only $0.12 \%$ variation in $h_{a}$ is obtained as shown in Figure 5. It is clear that the effect of grid size on the computed results diminishes for grids of 300,000 nodes. Therefore, the computing time can be, drastically, cut down to save computing time without a penalty of poor accuracy.

\section{Data Reduction}

4.1. Fluid Flow Considerations. The pressure drop coefficient, $P_{\mathrm{dc}}$, as defined below in (2) represents the ratio of the total pressure drop of the moving air through the tube bundle $\Delta P_{a}$ to its dynamic pressure:

$$
P_{\mathrm{dc}}=\frac{2 \Delta p_{a}}{\rho_{\mathrm{af}} \cdot{V_{\mathrm{ai}}}^{2}},
$$

where $\Delta P_{a}$ is the pressure drop through the tube bundle and $\rho_{\mathrm{af}}$ is the air film density and $V_{\mathrm{ai}}$ is the inlet air velocity.

$\operatorname{Re}_{a}$ and skin friction coefficient $C_{f}$ are denoted as

$$
\begin{aligned}
& \operatorname{Re}_{a}=\frac{\rho_{\mathrm{af}} V_{\mathrm{ai}} D_{\mathrm{eq}}}{\mu_{\mathrm{af}}}, \\
& C_{f}=\frac{\tau_{w}}{0.5 \rho V_{a}^{2}},
\end{aligned}
$$

where $\tau_{w}$ is the wall shear stress $\left(\mathrm{N} / \mathrm{m}^{2}\right)$. 


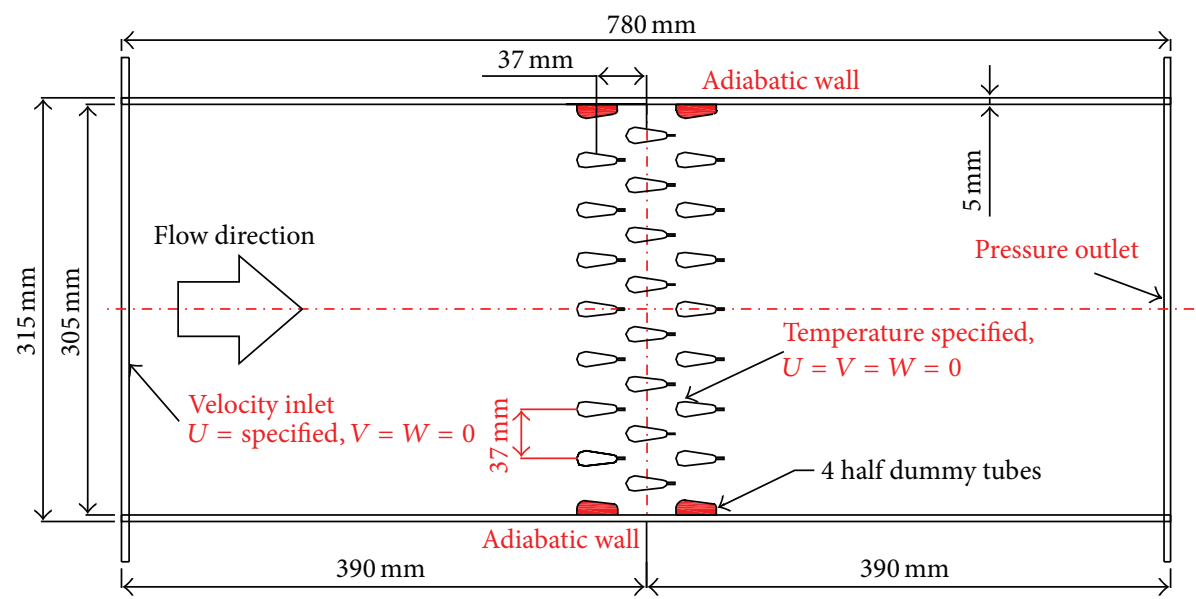

FIGURE 2: Schematic plane of the numerical domain with boundary conditions.
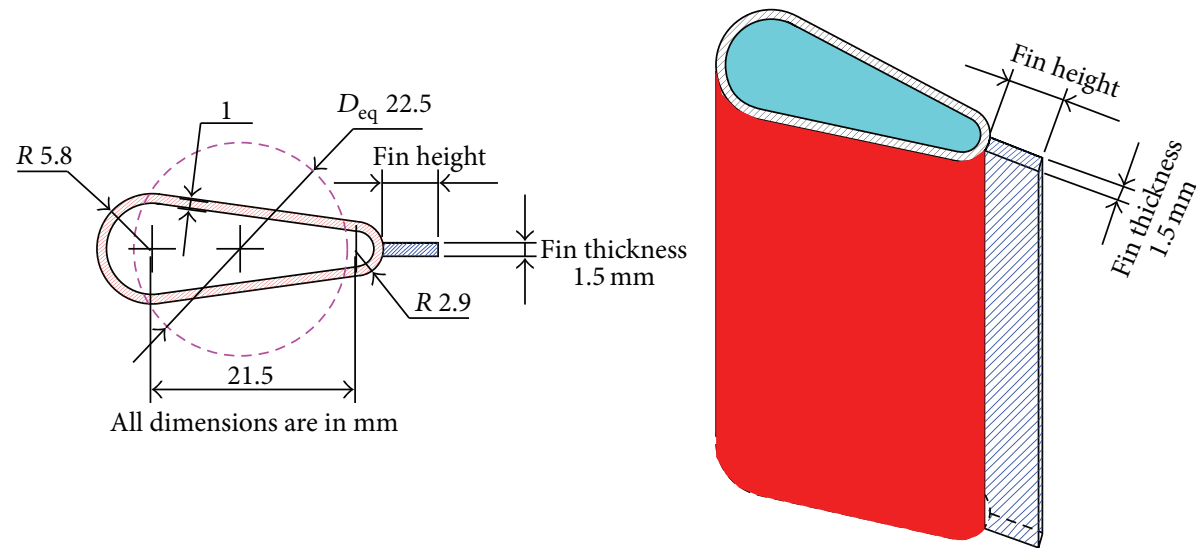

FIgURE 3: Wing-shaped tube cross-sectional dimensions with longitudinal fin.

\section{Results}

5.1. Validation of the Computational Model. The numerical results of the present study are validated with the corresponding experimental ones obtained by Sayed Ahmed et al. [18]. Figure 6 shows the validation of the experimental and numerical values of $P_{\mathrm{dc}}$ versus $\mathrm{Re}_{a}$ for wing-shaped tubes without fins (NOF). The average estimated error between the numerical and experimental results, at considered $\mathrm{Re}_{a}$, does not exceed $9 \%$.

5.2. Effect of $h_{f}$ and $\operatorname{Re}_{a}$ at Constant $(\delta=1.5 \mathrm{~mm})$ on Fluid Flow Characteristics of Heat Exchanger Performance. From the earliest study, it has been found that the wingshaped tubes heat exchangers have higher performance than those with circular and elliptical ones (Sayed Ahmed et al.) $[18,19]$. Further performance improvement requires the elimination of heat transfer deficiency in certain regions over the wing-shaped tubes. This suggests the placement of extended surface and/or protrusions in the deficient regions, where the separation of flow makes the heat transfer, mainly, by convection.
Fins is conducting heat outside of this region to the main flow where forced convection is dominant. Thus, fins act as a heat transfer cascade where the heat transfer conduction through the fins is followed by convection to the main flow downstream.

5.2.1. Air Flow Characteristics. Changing $h_{f}$ for the wingshaped tubes could affect the location at which separations and wakes were formed as well as the turbulence generation rate in the flow passing over the tubes. This in turn would have a direct effect on the resultant $\Delta P$ and on the heat exchange during the air cooling process. So, results will be portrayed by presenting the flow streamlines, velocity, and turbulent kinetic energy contours.

Flow-path-lines and velocity contours across the wingshaped tubes of the studied bundle arranged for different fin heights are illustrated in Figures 7-10. Up to $12 \mathrm{~mm}$ fin height as shown in Figure 7, at $\operatorname{Re}_{a}=1.8 \times 10^{3}$, for the arrangement of different fin heights there are three flow separation zones, two on the lateral sides and one at the rear surfaces of the tubes. This region is considered as a dead zone, where the separation of the flow makes the heat transfer mainly by 


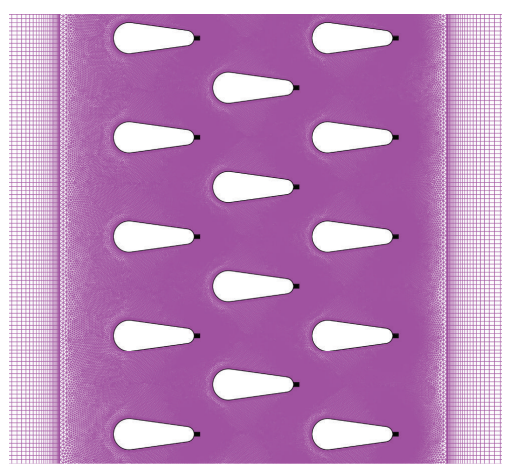

(a) $h_{f}=2 \mathrm{~mm}$

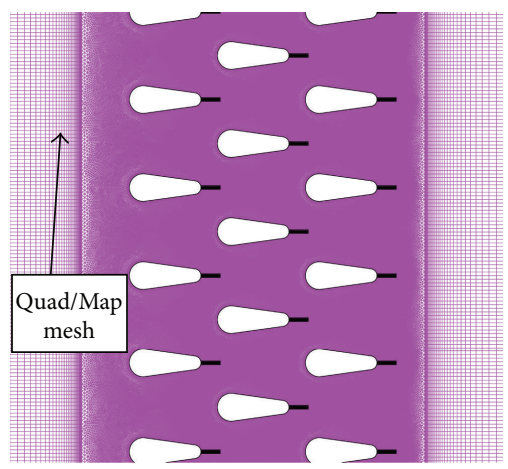

(d) $h_{f}=8 \mathrm{~mm}$

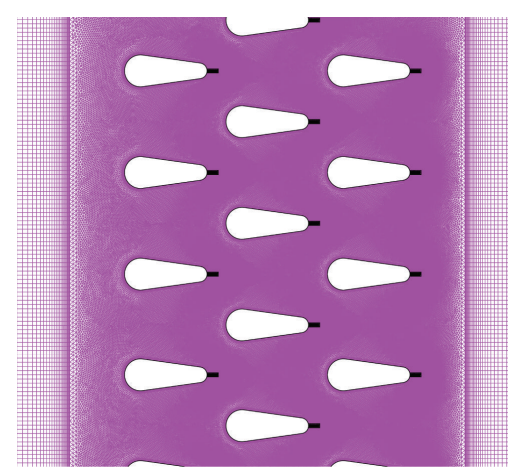

(b) $h_{f}=4 \mathrm{~mm}$

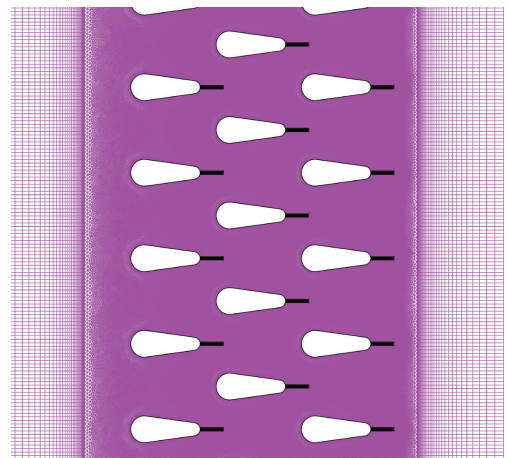

(e) $h_{f}=10 \mathrm{~mm}$

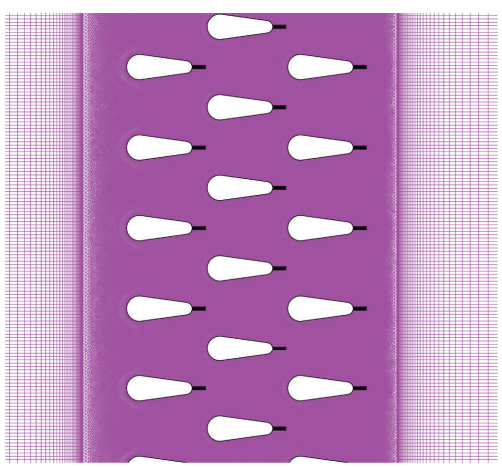

(c) $h_{f}=6 \mathrm{~mm}$

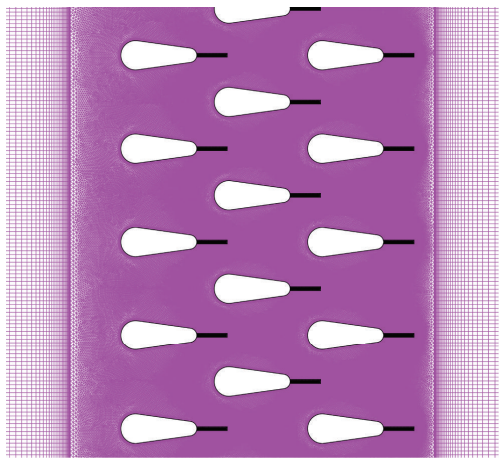

(f) $h_{f}=12 \mathrm{~mm}$

Figure 4: Mesh configurations for the domain of the tubes bundle.

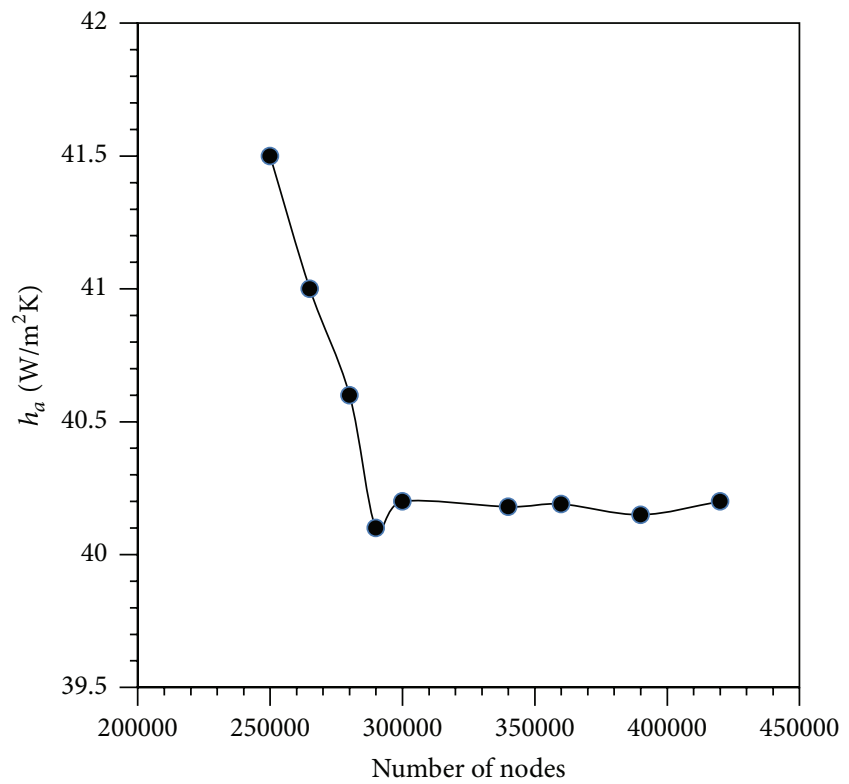

FIGURE 5: Effect of number of nodes of grid points on the computational $h_{a}$.

natural convection. Flow separations occurred, as a result of travelling of the boundary layer far enough against an adverse pressure gradient that makes the velocity of the boundary layer fall, almost, to zero. On the other hand, flow separation

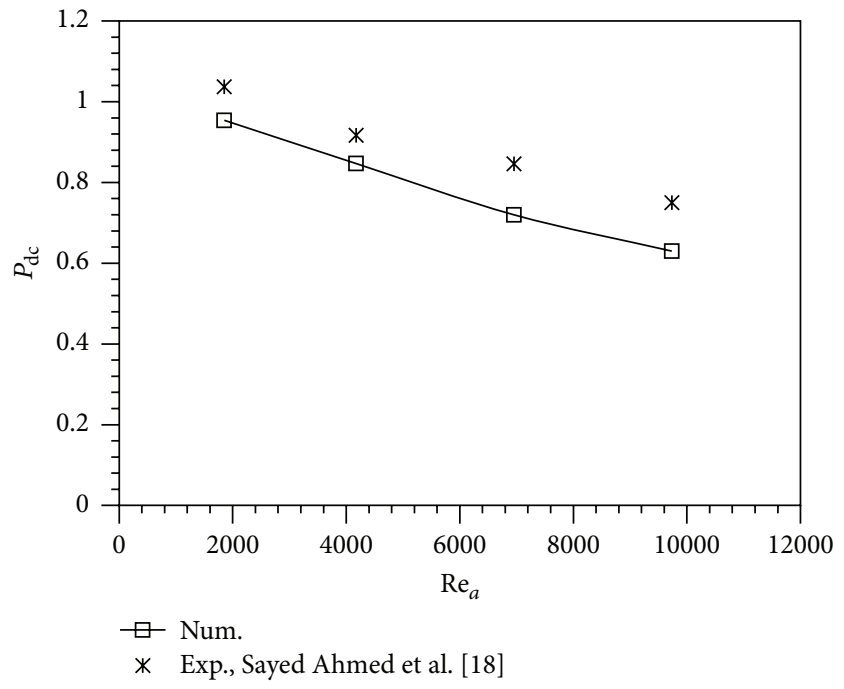

FIGURE 6: Validation of the experimental and numerical values of $P_{\mathrm{dc}}$ versus $\mathrm{Re}_{a}$ for NOF.

can occur as a result of the increase of the pressure drag caused by the pressure differential of the flowing air between the frontal and rear surfaces of the tube.

On the other hand, for high $\mathrm{Re}_{a}$, as shown in Figure 8, separations and secondary flows intensity occurred, mainly, on the rear surfaces of the tubes. It is seen from Figure 8 that, 


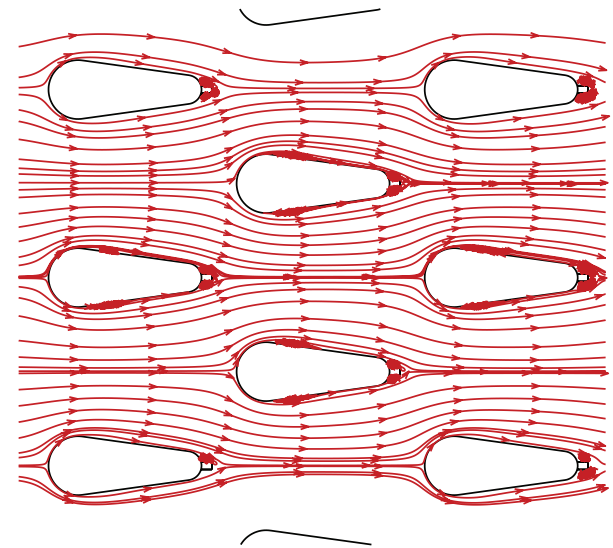

(a)

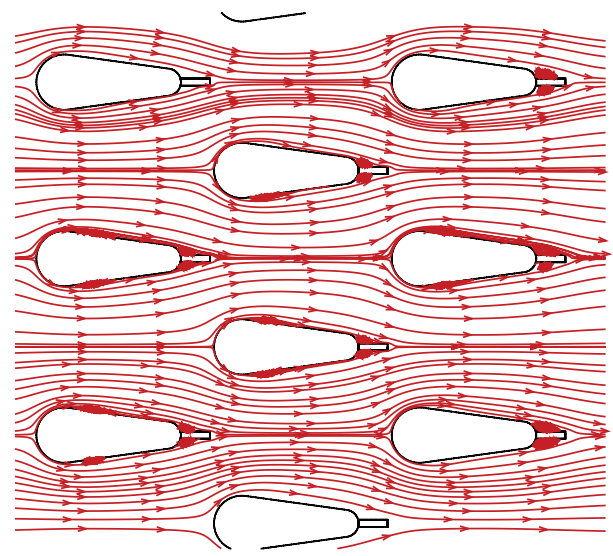

(c)

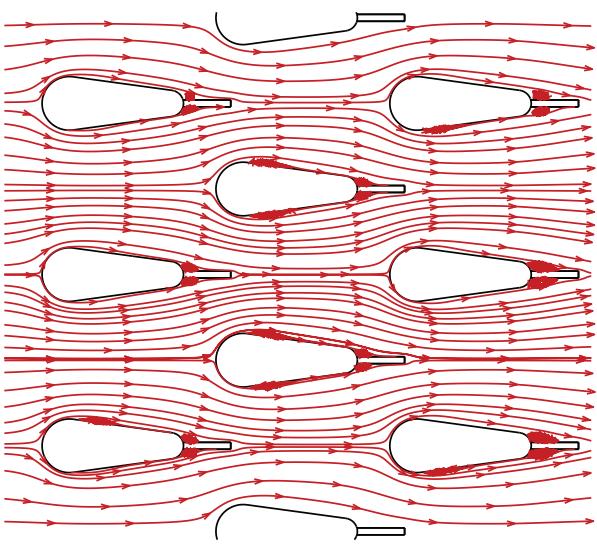

(e)

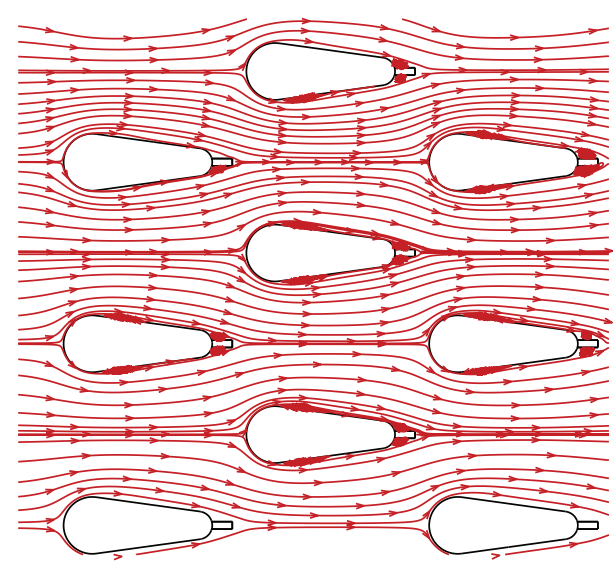

(b)

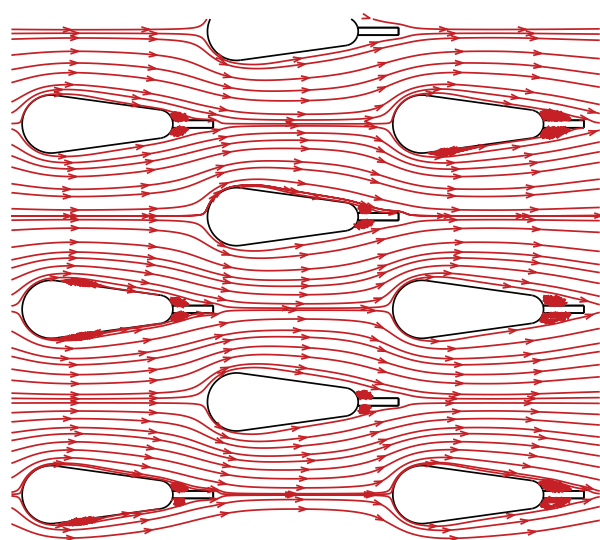

(d)

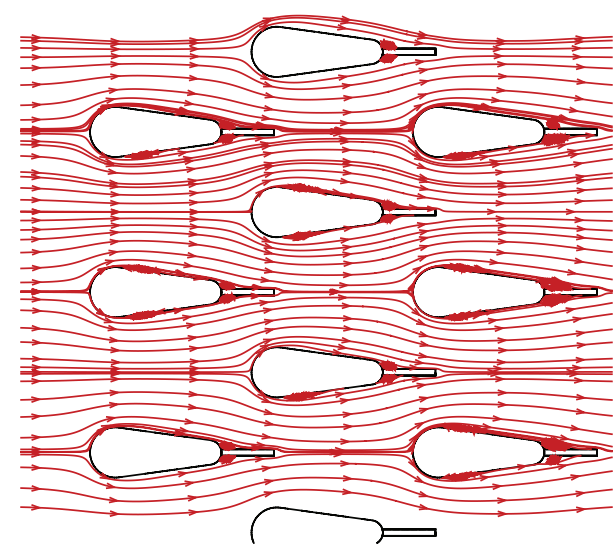

(f)

Figure 7: Air flow path-lines of the wing-shaped tubes bundle for different fin heights $\left(h_{f}\right)$ at $\operatorname{Re}=1800$ : (a) $h_{f}=2 \mathrm{~mm}$, (b) $h_{f}=4 \mathrm{~mm}$, (c) $h_{f}=6 \mathrm{~mm},(\mathrm{~d}) h_{f}=8 \mathrm{~mm},(\mathrm{e}) h_{f}=10 \mathrm{~mm}$, and (f) $h_{f}=12 \mathrm{~mm}$.

with increasing fin height, eddies and vortices at lateral tube surfaces disappeared. This is due to the fact that, for high $\mathrm{Re}_{a}$, the flow becomes more energetic enabling the boundary layer to travel further along with the tube surface before separation occurs resulting, only, in a narrower wake at the rear surface of the tube.

As seen from Figures 9 and 10, the air flow is strongly accelerated in the passages between tubes. With increasing of fin heights and/or $\mathrm{Re}_{a}$ the flow is strongly guided between the tubes and the deficient flow separation zones are delayed and/or disappeared. Also, the levels of turbulence and formation of vortices through the passages of the bundle are increased.

Figures 11 and 12 present the turbulent kinetic energy contours through the wing-shaped tubes of the bundle for both low and high $\mathrm{Re}_{a}$, which is defined as the mean kinetic 


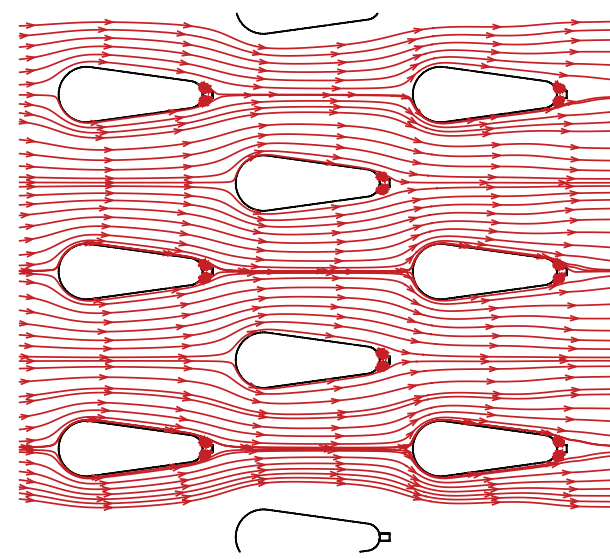

(a)

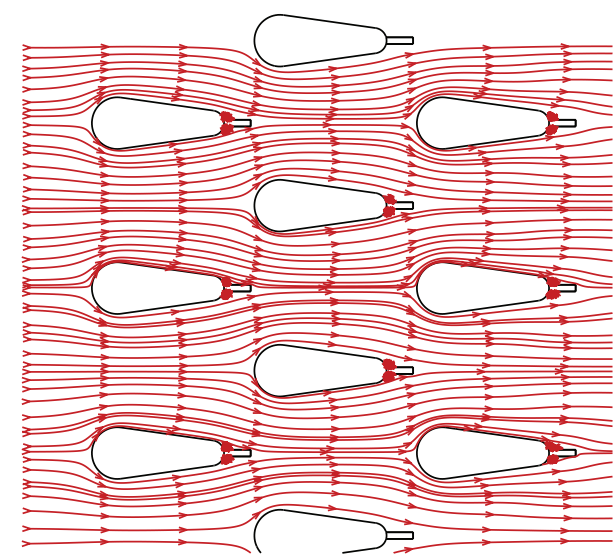

(c)

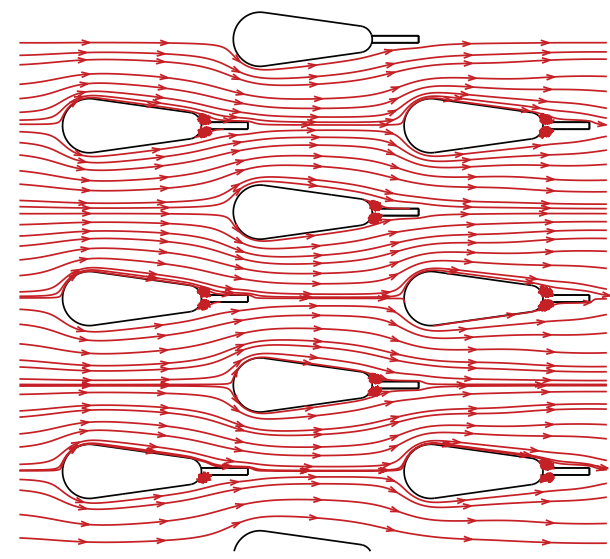

(e)

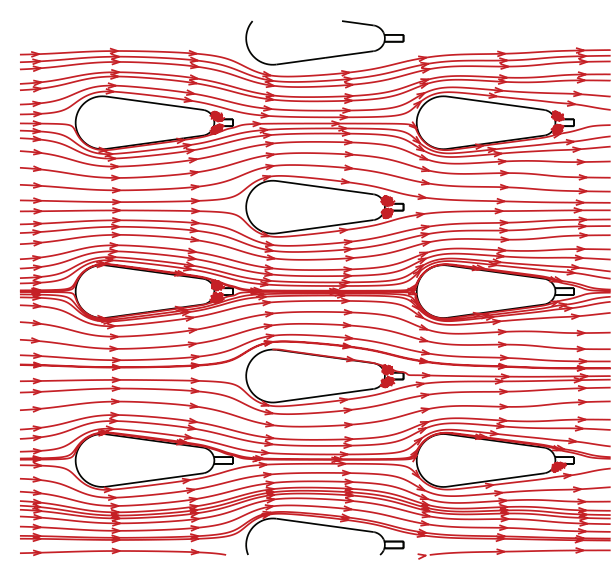

(b)

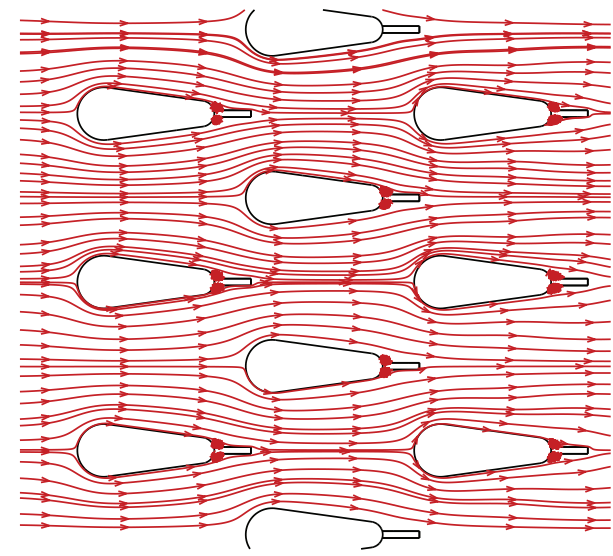

(d)

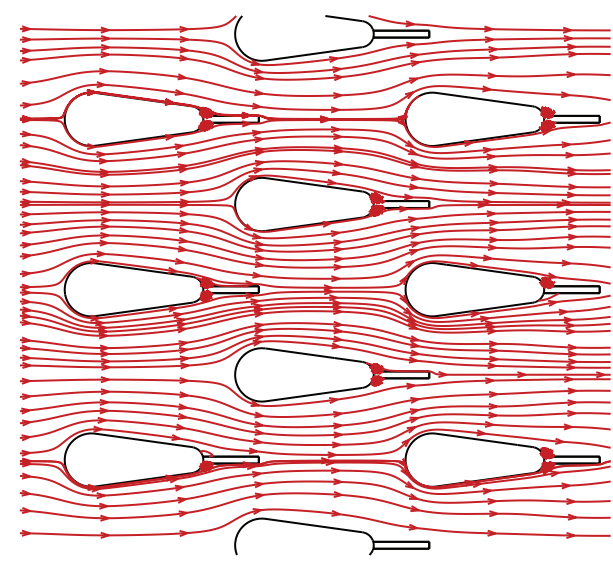

(f)

Figure 8: Air flow path-lines of the wing-shaped tubes bundle for different fin heights $\left(h_{f}\right)$ at $\operatorname{Re}=9700:(\mathrm{a}) h_{f}=2 \mathrm{~mm},(\mathrm{~b}) h_{f}=4 \mathrm{~mm},(\mathrm{c})$ $h_{f}=6 \mathrm{~mm},(\mathrm{~d}) h_{f}=8 \mathrm{~mm},(\mathrm{e}) h_{f}=10 \mathrm{~mm}$, and (f) $h_{f}=12 \mathrm{~mm}$.

energy per unit mass associated with eddies in turbulent flow. Physically, the turbulent kinetic energy produced by friction and buoyancy forces or through external forcing at low-frequency Eddie scales (integral scale) is characterized via root-mean-square method (RMS). Turbulence kinetic energy is transferred down the turbulence energy cascade and dissipated by viscous forces at the Kolmogorov scale (smallest scales in the spectrum that form the viscous sublayer range). It is found that the turbulent kinetic energy is larger in magnitude in the case of higher $\mathrm{Re}_{a}$. This, in turn, enhances the fluid flow characteristics. It is, also, seen from the figures that there is a direct proportionality between $\operatorname{Re}_{a}$ and the values of turbulent kinetic energy $(k)$ but the numerical results show that the values of $k$ at the exit section of 


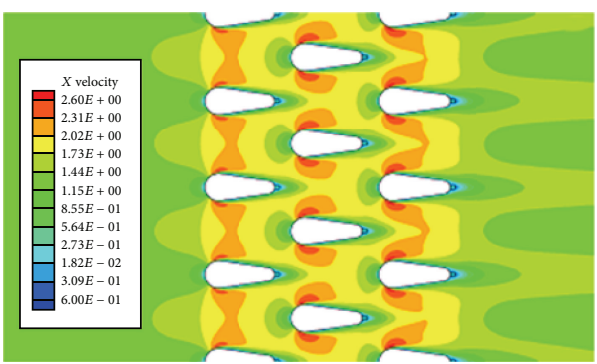

(a)

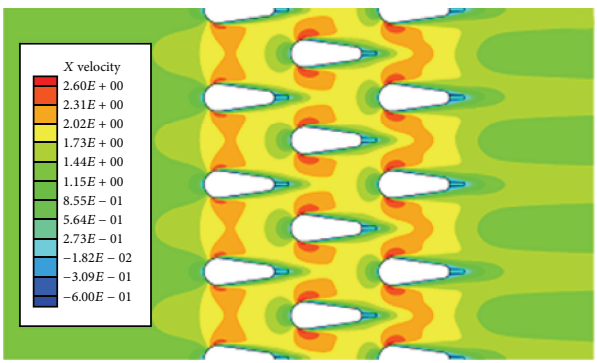

(c)

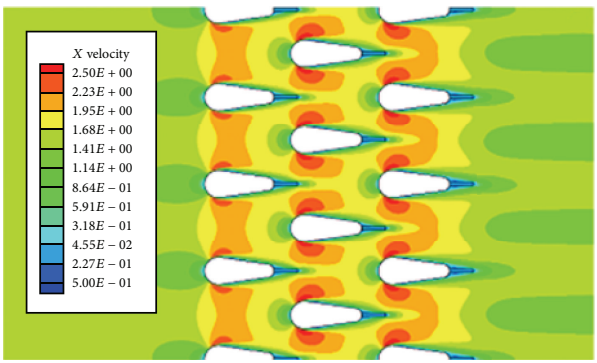

(e)

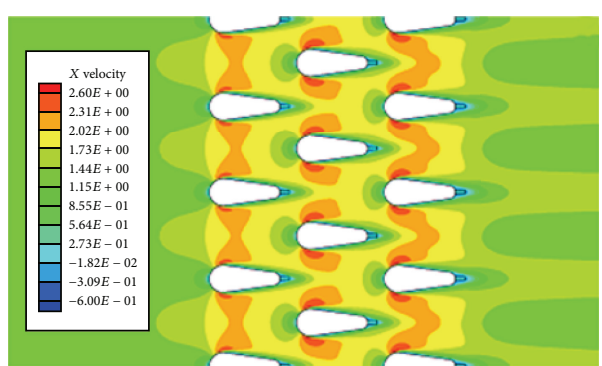

(b)

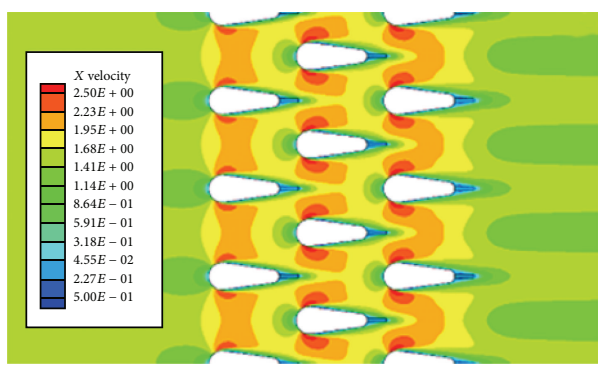

(d)

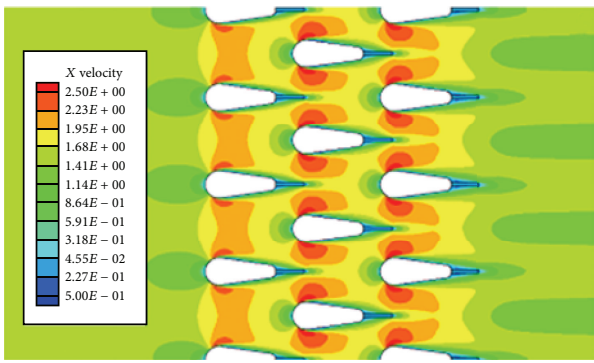

(f)

Figure 9: Velocity contours (m/s) of the wing-shaped tubes bundle for different fin heights $\left(h_{f}\right)$ at $\operatorname{Re}=1800:(\mathrm{a}) h_{f}=2 \mathrm{~mm}$, (b) $h_{f}=4 \mathrm{~mm}$, (c) $h_{f}=6 \mathrm{~mm},(\mathrm{~d}) h_{f}=8 \mathrm{~mm},(\mathrm{e}) h_{f}=10 \mathrm{~mm}$, and (f) $h_{f}=12 \mathrm{~mm}$.

the bundle are always greater than those at the inlet one for considered $\mathrm{Re}_{a}$ range, so the bundle works as a turbulence generator which leads to an increase in the heat transfer between tubes and flowing air. With the increasing of $h_{f}$ the values of $k$ increase at the fin tip leading to the enhancement of heat transfer over the following rows of the bundle. So, the fin acts as a turbulent generator.

5.2.2. Air Flow Pressure Drop through the Bundle. Figures 13 and 14 demonstrate the static pressure contours through the bundle. It can be seen that the pressure has the highest values at the stagnation point on the frontal portion of each tube, at which the flow velocity tends to be zero. As the flow passes over the tube surface, the pressure decreases until reaching its lowest value at the tube lateral surface.

Figure 15 shows the variation of $\Delta P_{a}$ versus $\operatorname{Re}_{a}$ at different $h_{f}$. It is seen from the figure that $\Delta P_{a}$ increases with the increase of $\operatorname{Re}_{a}$ for different $h_{f}$. Figure 16 shows the variation of $\Delta P_{a}$ versus various $h_{f}$ at different values of $\operatorname{Re}_{a} . \Delta P_{a}$ decreases with $h_{f}$ for $2 \mathrm{~mm} \leq h_{f} \leq 6 \mathrm{~mm}$, while there is no significant change of $\Delta P_{a}$ for $6 \mathrm{~mm}<h_{f} \leq 12 \mathrm{~mm}$ except for slight increasing of $\Delta P_{a}$ at $6 \mathrm{~mm}<h_{f} \leq 12 \mathrm{~mm}$ for $\operatorname{Re}_{a}=9700$. Lowest values of $\Delta P_{a}$ occurred for arrangements of $h_{f}=6 \mathrm{~mm}$.

Figure 17 shows the variation of $P_{\mathrm{dc}}$ versus $\mathrm{Re}_{a}$ at different $h_{f}$. It is seen from the figure that $P_{\mathrm{dc}}$ decreases with $\mathrm{Re}_{a}$ for NOF. $P_{\mathrm{dc}}$ has the highest values for all studied $h_{f}$ at $\operatorname{Re}_{a}=$ 2000 and decreases with the increase of $\mathrm{Re}_{a}$ in the range of $1800 \leq \mathrm{Re}_{a} \leq 4200$ and then increases for $4200 \leq \mathrm{Re}_{a} \leq 10000$ for all tested fins. Lowest values of $P_{\mathrm{dc}}$ occurred at $h_{f}=6 \mathrm{~mm}$. The values of $P_{\mathrm{dc}}$ for $h_{f}=6 \mathrm{~mm}$ are lower than those of NOF and $h_{f}=2 \mathrm{~mm}$ by about $73 \%$ and $32 \%$, respectively, at $\operatorname{Re}_{a}=$ 4000 .

Figure 18 shows the variation of $P_{\mathrm{dc}}$ versus various $h_{f}$ at different values of $\operatorname{Re}_{a} \cdot P_{\mathrm{dc}}$ decreases with $h_{f}$ for $2 \mathrm{~mm} \leq h_{f} \leq$ $6 \mathrm{~mm}$, while $P_{\mathrm{dc}}$ increases with $6 \mathrm{~mm}<h_{f} \leq 12 \mathrm{~mm}$ for the considered $\mathrm{Re}_{a}$ range.

These results can be attributed to the fact that the overall drag consists of two combined parts; one presents the pressure drag while the other presents the friction drag. The friction drag is more dominant than the pressure drag at the lower $\mathrm{Re}_{a}$, thus leading to higher pressure drop while the opposite is true at higher $\operatorname{Re}_{a}$. In the case of high $\operatorname{Re}_{a}$, 


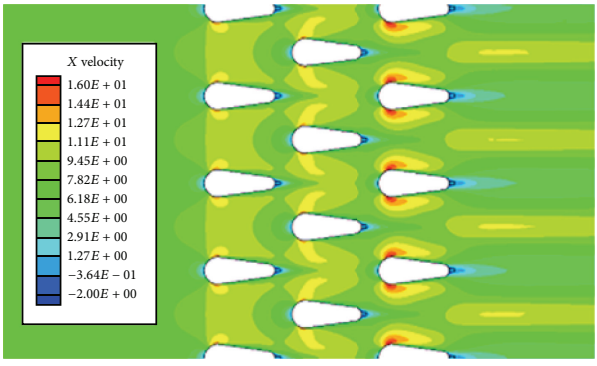

(a)

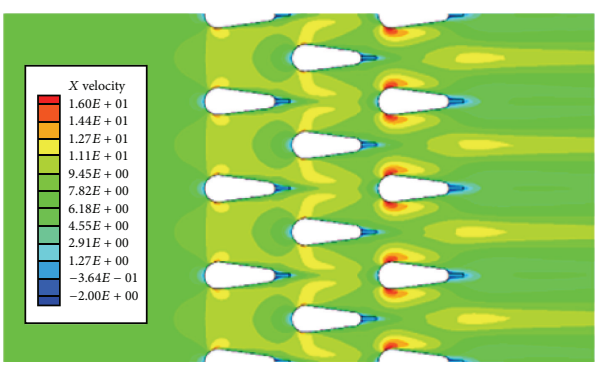

(c)

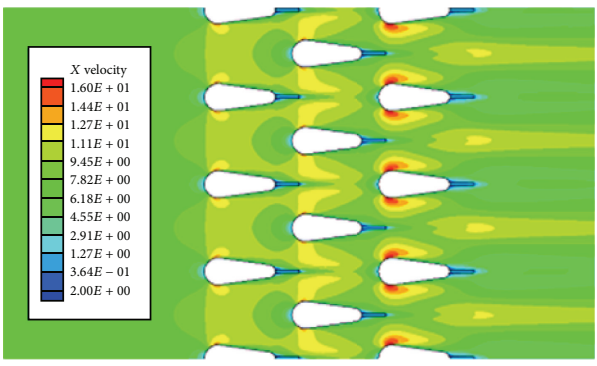

(e)

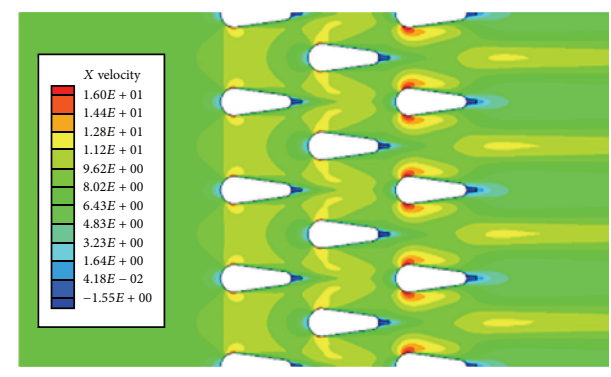

(b)

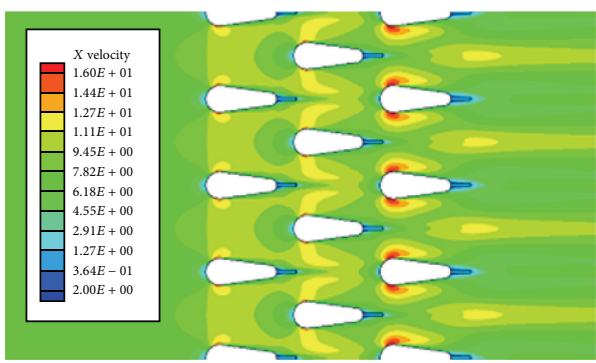

(d)

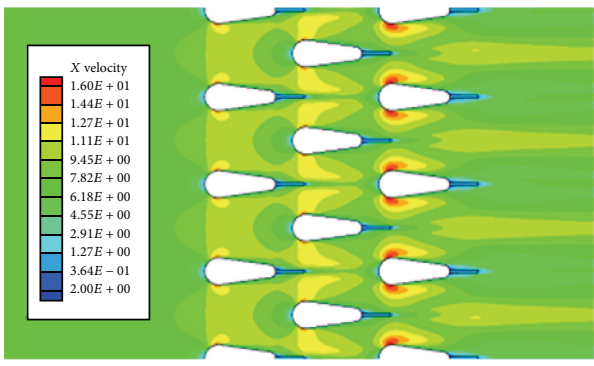

(f)

FiguRE 10: Velocity contours (m/s) of the wing-shaped tubes bundle for different fin heights $\left(h_{f}\right)$ at $\operatorname{Re}=9700:(\mathrm{a}) h_{f}=2 \mathrm{~mm}$, (b) $h_{f}=4 \mathrm{~mm}$, (c) $h_{f}=6 \mathrm{~mm},(\mathrm{~d}) h_{f}=8 \mathrm{~mm},(\mathrm{e}) h_{f}=10 \mathrm{~mm}$, and (f) $h_{f}=12 \mathrm{~mm}$.

the effect of viscosity is less dominant and the total drag is rather affected by the inertia forces. As the flow tends to shift towards more turbulent region, the separation region, also, travels farther downstream, reducing the size of the wake and the magnitude of the pressure drag.

5.2.3. Skin Friction Coefficient $\left(C_{f, m}\right)$. The distribution of average skin friction coefficient around wing-shaped tubes bundle is studied. Figures 19 and 20 show the effect of $h_{f}$ on average $C_{f, m}$ at different $\operatorname{Re}_{a}$ for wing-shaped tubes bundle. $C_{f, m}$ decreases as $\operatorname{Re}_{a}$ increases. It can be observed that there is no significant difference in the values of $C_{f, m}$ for different arrangements at considered $\mathrm{Re}_{a}$.

This phenomenon may be explained as follows. For the baseline case NOF, the air flow resistance from the inlet to outlet of the heat exchanger arises from the local resistance of the wing-shaped tubes, which plays dominant part of the total pressure drop. When the LFTHs are installed, the air flow resistance will arise from the tubes and the local resistance of the LFTH. LFTH brings about additional form drag and delays the separation of boundary layer from the wing-shaped tubes and decreases the wake region behind the tube so that the form drag from the tubes decreases. Therefore, the LFTH with $h_{f}=6 \mathrm{~mm}$ offers lower form drag than that with $h_{f}=12 \mathrm{~mm}$ and that of NOF. Thus, the case of $h_{f}=6 \mathrm{~mm}$ increases the heat transfer and decreases $C_{f, m}$ compared with the base case of NOF.

5.2.4. Selection of Best Arrangement for Lowest Pumping Power $(P P)$. One of the goals of this study is to predict optimal $h_{f}$ that would minimize the frictional losses of the flow. A typical plot is provided to compromise between $h_{f}$ and the pumping power (PP). A relationship (4) was obtained on multiplying the pressure drop and the volumetric flow rate as

$$
\mathrm{PP}=\Delta P_{a} \cdot \mathrm{FR}_{a, i},
$$

where $\Delta P$ is pressure drop $(\mathrm{Pa}) . \mathrm{FR}_{a, i}$ is air volume flow rate $\left(\mathrm{m}^{3} / \mathrm{s}\right)$.

Figure 21 shows the variation of $\mathrm{PP}$ versus $\mathrm{Re}_{a}$ at different $h_{f}$. It is seen from the figure that PP increases with the increase of $\mathrm{Re}_{a}$ for arrangements with different $h_{f}$. Figure 22 shows the effect of $h_{f}$ on PP at different $\mathrm{Re}_{a}$. At certain $\mathrm{Re}_{a}$, PP decreases with $h_{f}$ from $2 \mathrm{~mm} \leq h_{f} \leq 6 \mathrm{~mm}$, while the 


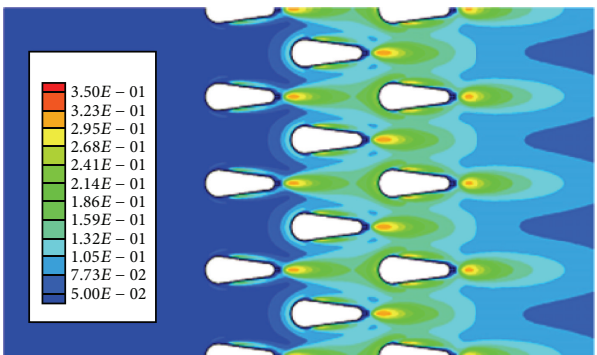

(a)

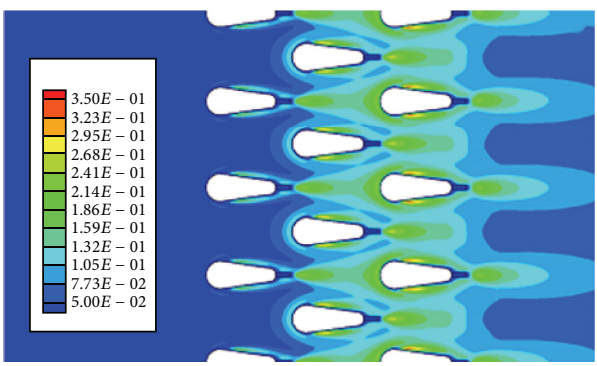

(c)

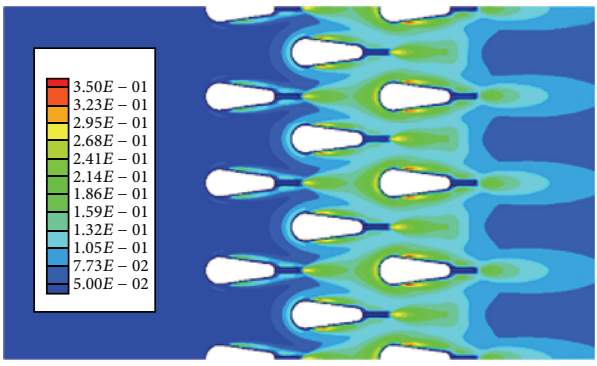

(e)

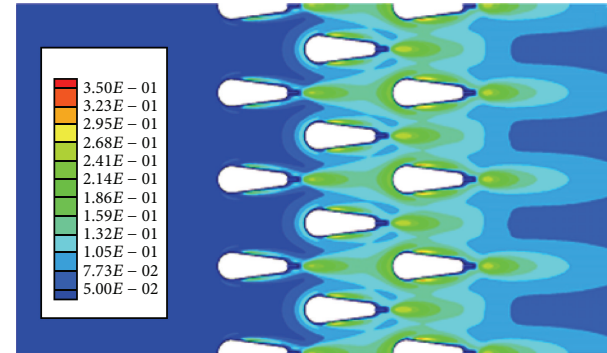

(b)

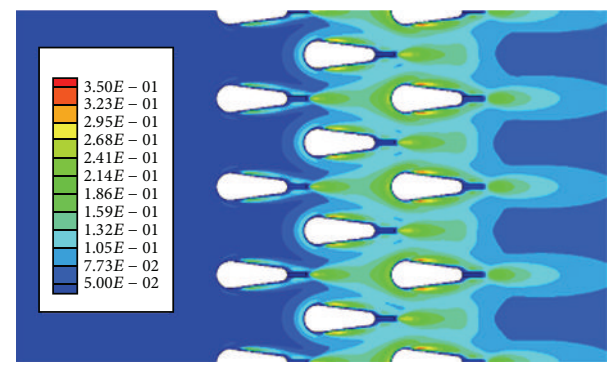

(d)

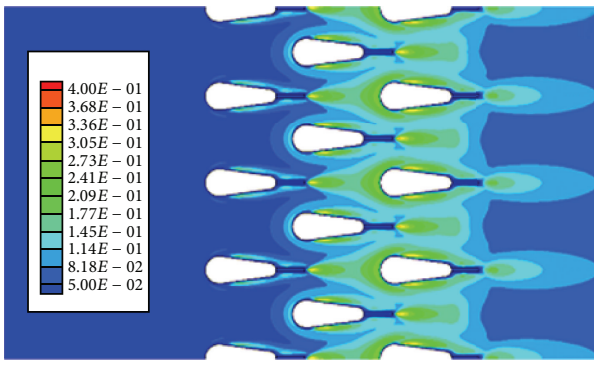

(f)

FIGURE 11: Turbulent kinetic energy contours $\left(\mathrm{m}^{2} / \mathrm{s}^{2}\right)$ of the wing-shaped tubes for different fin heights $\left(h_{f}\right)$ at $\operatorname{Re}=1800:(\mathrm{a}) h_{f}=2 \mathrm{~mm}$, (b) $h_{f}=4 \mathrm{~mm},(\mathrm{c}) h_{f}=6 \mathrm{~mm},(\mathrm{~d}) h_{f}=8 \mathrm{~mm},(\mathrm{e}) h_{f}=10 \mathrm{~mm}$, and (f) $h_{f}=12 \mathrm{~mm}$.

variation of PP is negligible for $6 \mathrm{~mm}<h_{f} \leq 12 \mathrm{~mm}$. The figure shows, also, that the lowest values of the pumping power are achieved for arrangements of $h_{f}=6 \mathrm{~mm}$ for the considered $\mathrm{Re}_{a}$ range.

This is due to the fact that the wing-shaped tubes bundle arrangement promoted turbulent mixing and lengthened the air flow path through the bundle. The size and the strength of the turbulence level as well as the reversed flow region are affected by $h_{f}$ and $\operatorname{Re}_{a}$ variations.

5.3. Effect of $\delta$ at Constant $\left(h_{f}=6 \mathrm{~mm}\right)$ on $\Delta P_{a}$ and $C_{f, m}$. Figures 23 and 24 show the effect of $\delta$ on $\Delta P_{a}$ and $C_{f, m}$ for different $\operatorname{Re}_{a}$ at constant $h_{f}=6 \mathrm{~mm}$. It is clear from Figure 23 that $\delta$ has negligible effect on $C_{f, m}$ and the highest values of $C_{f, m}$ are obtained for $\operatorname{Re}_{a}=1850$ while the lowest ones belong to $\operatorname{Re}_{a}=9700$. Figure 24 shows a variation in $\Delta P_{a}$ values for the considered $\delta$ range, where $\Delta P_{a}$ increases for $1.5 \mathrm{~mm} \leq \delta \leq$ $2.5 \mathrm{~mm}$ while $\Delta P_{a}$ decreases with $2.5 \mathrm{~mm}<\delta \leq 3.5 \mathrm{~mm}$ for the considered $\mathrm{Re}_{a}$ range except for $\mathrm{Re}_{a}=1850$ where there is no significant change of $\Delta P_{a}$ for $1.5 \mathrm{~mm} \leq \delta \leq 3.5 \mathrm{~mm}$.

\section{Correlations of the Results}

Correlations for $P_{\mathrm{dc}}$ and $C_{f, m}$ based on the numerical results obtained in terms of Re and $h_{f} / D_{\text {eq }}$ are predicted by (5) and (6), using power regression, as follows:

$$
\begin{aligned}
P_{\mathrm{dc}}= & a+b\left(\mathrm{Re}_{a}\right)^{-1}+c\left(\mathrm{Re}_{a}\right)^{-2}+d\left(\frac{h_{f}}{D_{\mathrm{eq}}}\right) \\
& +e\left(\frac{h_{f}}{D_{\mathrm{eq}}}\right)^{2}, \\
C_{f, m}= & a \cdot\left(\mathrm{Re}_{a}\right)^{b} \cdot\left(\frac{h_{f}}{D_{\mathrm{eq}}}\right)^{c},
\end{aligned}
$$

where $D_{\text {eq }}$ is the equivalent circular diameter.

Table 1 shows all constants with maximum percentage difference (max. diff. \%) between the calculated and obtained results for (5) and (6). The excellent $R^{2}$ values confirm the statistical goodness of the fit. The obtained correlations are applicable for $1.8 \times 10^{3} \leq \mathrm{Re}_{a} \leq 9.7 \times 10^{3}$. 


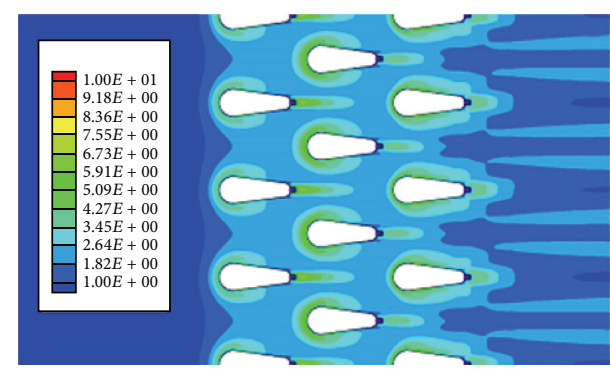

(a)

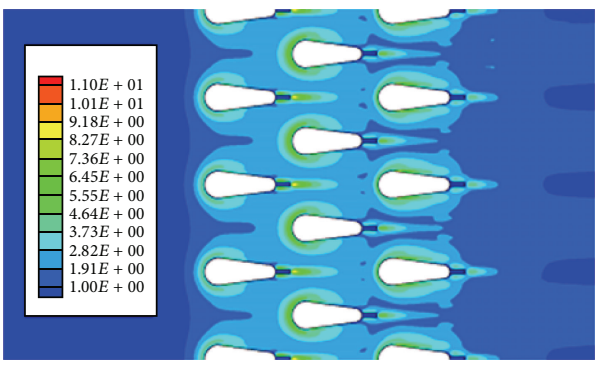

(c)

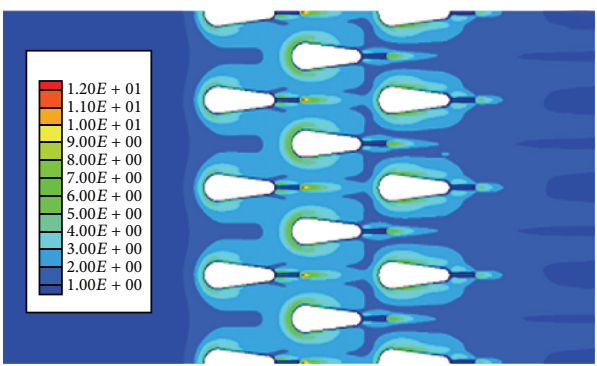

(e)

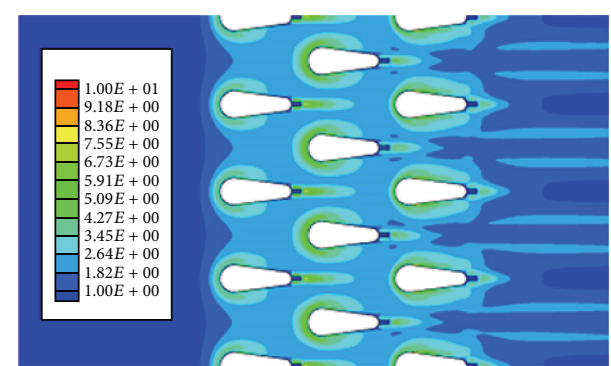

(b)

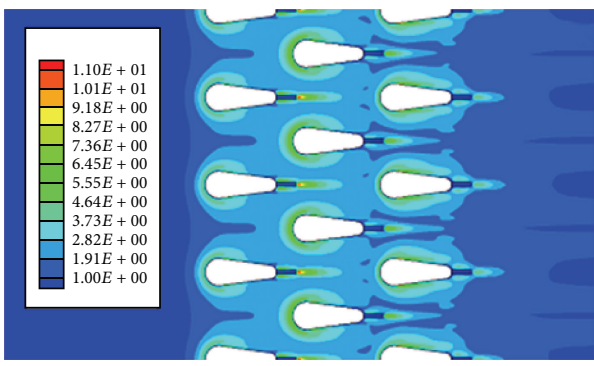

(d)

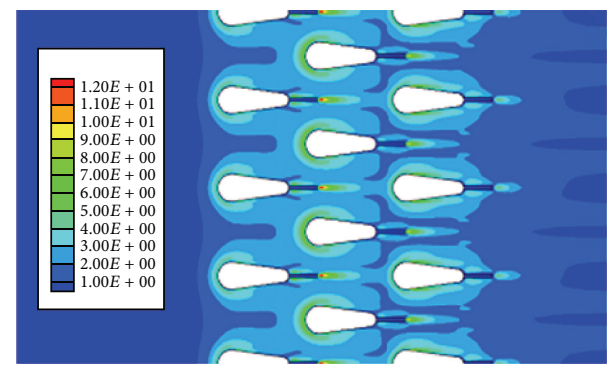

(f)

FIGURE 12: Turbulent kinetic energy contours $\left(\mathrm{m}^{2} / \mathrm{s}^{2}\right)$ of the wing-shaped tubes for different fin heights $\left(h_{f}\right)$ at $\operatorname{Re}=9700:(\mathrm{a}) h_{f}=2 \mathrm{~mm}$, (b) $h_{f}=4 \mathrm{~mm},(\mathrm{c}) h_{f}=6 \mathrm{~mm},(\mathrm{~d}) h_{f}=8 \mathrm{~mm},(\mathrm{e}) h_{f}=10 \mathrm{~mm}$, and (f) $h_{f}=12 \mathrm{~mm}$.

TABLE 1: Constants for (5) and (6).

\begin{tabular}{lccccccc}
\hline $\begin{array}{l}\text { Equation } \\
\text { number }\end{array}$ & $a$ & $b$ & $c$ & $d$ & $e$ & $R^{2}$ & $\begin{array}{c}\text { Max. } \\
\text { diff. \% }\end{array}$ \\
\hline$(5)$ & 1.47 & -4574.84 & $7416.5 \times 10^{3}$ & -1.1 & 1.823 & 0.9 & \pm 9 \\
$(6)$ & 1.042 & -0.405 & -5.203 & - & - & 0.99 & \pm 4 \\
\hline
\end{tabular}

\section{Conclusions}

Improvement of wing-shaped tubes bundle performance requires the elimination of fluid flow deficiency in certain regions over the tubes. This suggests the placement of extended surface in the deficient regions, where the separation of flow makes the heat transfer, mainly, by natural convection. A numerical study has been conducted to clarify fluid flow characteristics, pressure drop distributions, and $C_{f, m}$ over a wing-shaped tubes bundle in staggered arrangement with the placement of LF on downstream side of the tube. $\operatorname{Re}_{a}$ ranged from $1.8 \times 10^{3}$ to $9.7 \times 10^{3}$. The tubes bundles are equipped with various fins having $2 \mathrm{~mm} \leq h_{f} \leq 12 \mathrm{~mm}$ and $1.5 \mathrm{~mm} \leq \delta \leq 3.5 \mathrm{~mm}$ at considered $\mathrm{Re}_{a}$ range. The flow pattern around the staggered wing-shaped tubes bundle is predicted using the commercial CFD FLUENT 6.3.26 software package. Correlations of pressure drop coefficient $P_{\mathrm{dc}}$ and skin friction coefficient $\left(C_{f, m}\right)$ in terms of $\mathrm{Re}_{a}$, design parameters, for the studied cases are presented. Comparisons between the experimental and numerical results of the present study and those, previously, obtained for similar available studies showed good agreements. Results indicate that the attaching of LF to the tubes surfaces downstream acts as a heat transfer cascade where heat transfers firstly by conduction through the fins and then followed by convection to the main flow downstream. The following conclusions are preferred:

(i) $\Delta P_{a}$ increases with of $\operatorname{Re}_{a}$ for LF with different $h_{f}$. $\Delta P_{a}$ decreases with $h_{f}$ for $2 \mathrm{~mm} \leq h_{f} \leq 6 \mathrm{~mm}$, while there is no significant change of $\Delta P_{a}$ for $6 \mathrm{~mm}<h_{f} \leq$ $12 \mathrm{~mm}$ except for slight increasing of $\Delta P_{a}$ at $6 \mathrm{~mm}<$ $h_{f} \leq 12 \mathrm{~mm}$ for $\operatorname{Re}_{a}=9700$. Lowest values of $\Delta P_{a}$ occurred for arrangements of $h_{f}=6 \mathrm{~mm}$. 


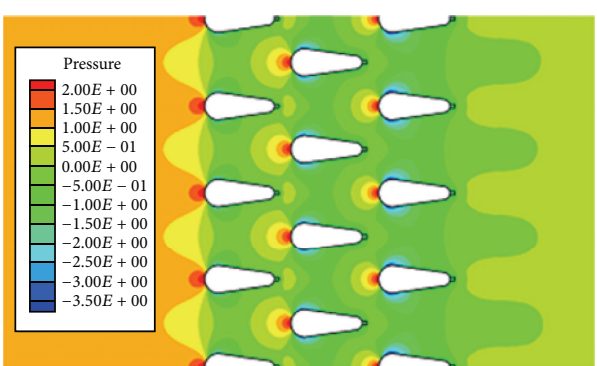

(a)

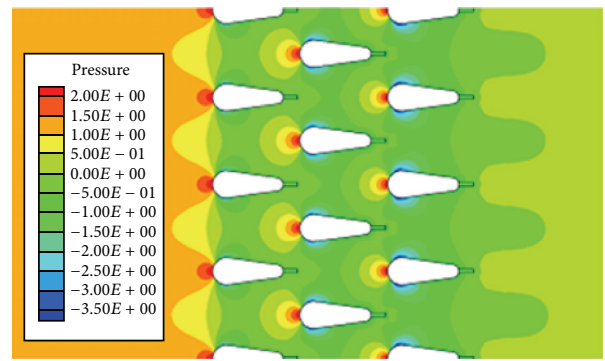

(c)

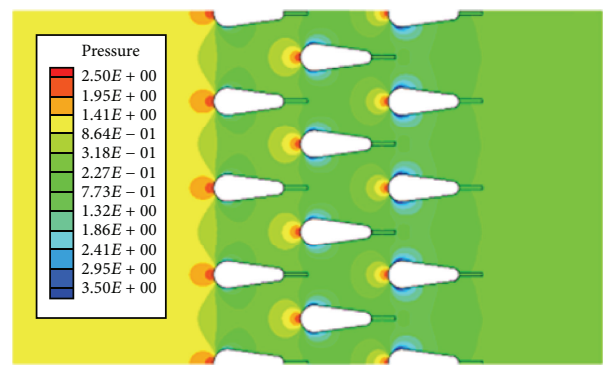

(e)

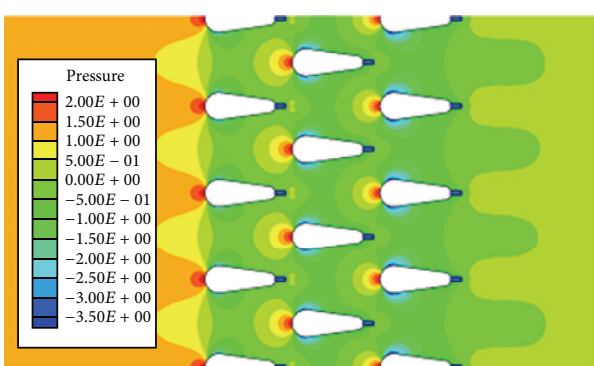

(b)

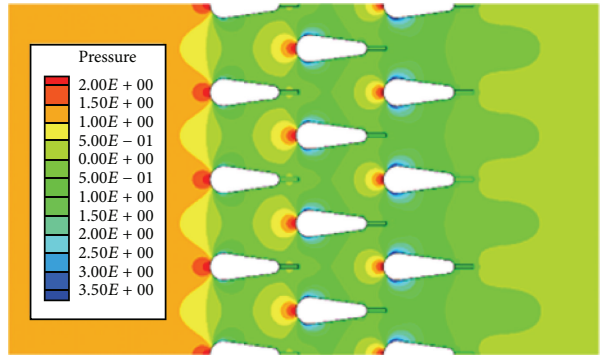

(d)

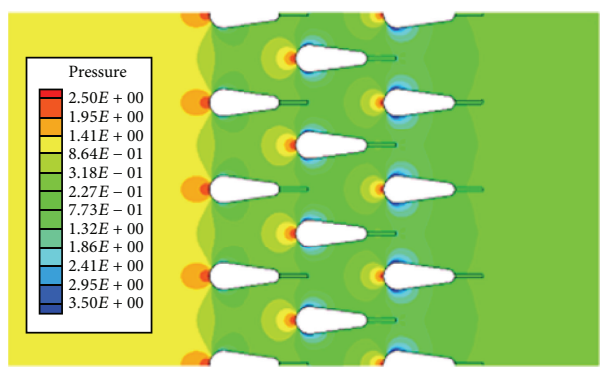

(f)

Figure 13: Static pressure contours (Pa) through the wing-shaped tubes bundle for different fin heights $\left(h_{f}\right)$ at $\operatorname{Re}=1800:(\mathrm{a}) h_{f}=2 \mathrm{~mm},(\mathrm{~b})$ $h_{f}=4 \mathrm{~mm},(\mathrm{c}) h_{f}=6 \mathrm{~mm},(\mathrm{~d}) h_{f}=8 \mathrm{~mm},(\mathrm{e}) h_{f}=10 \mathrm{~mm}$, and (f) $h_{f}=12 \mathrm{~mm}$.

(ii) $P_{\mathrm{dc}}$ has the highest values for all studied $h_{f}$ at $\operatorname{Re}_{a}=$ 2000 , and $P_{\mathrm{dc}}$ decreases with the increase of $\mathrm{Re}_{a}$ in the range of $1800 \leq \mathrm{Re}_{a} \leq 4200$ and then increases for $4200 \leq \operatorname{Re}_{a} \leq 10000$ for all tested fins. Lowest values of $P_{\mathrm{dc}}$ occurred at $h_{f}=6 \mathrm{~mm}$.

(iii) $P_{\mathrm{dc}}$ decreases with $h_{f}$ for $2 \mathrm{~mm} \leq h_{f} \leq 6 \mathrm{~mm}$, while $P_{\mathrm{dc}}$ increases for $6 \mathrm{~mm}<h_{f} \leq 12 \mathrm{~mm}$ with considered $\operatorname{Re}_{a}$. The values of $P_{\mathrm{dc}}$ for $h_{f}=6 \mathrm{~mm}$ are lower than those of NOF and $h_{f}=2 \mathrm{~mm}$ by about $73 \%$ and $32 \%$, respectively, at $\operatorname{Re}_{a}=4000$.

(iv) $C_{f, m}$ decreases as $\operatorname{Re}_{a}$ increases for all studied fins. The use of LF with $h_{f}=6 \mathrm{~mm}$ results in decreasing average $C_{f, m}$ compared with these of the case of NOF.

(v) PP increases with the increase of $\mathrm{Re}_{a}$ for arrangements with different $h_{f}$. PP decreases with $h_{f}$ from $2 \mathrm{~mm} \leq h_{f} \leq 6 \mathrm{~mm}$, while the variation of PP is negligible for $6 \mathrm{~mm}<h_{f} \leq 12 \mathrm{~mm}$. The lowest values of PP are achieved for arrangements of $h_{f}=6 \mathrm{~mm}$ for the considered $\mathrm{Re}_{a}$ range.

(vi) $\delta$ has negligible effect on $C_{f, m}$ and the highest values of $C_{f, m}$ are obtained for $\operatorname{Re}_{a}=1850$ while the lowest ones belong to $\operatorname{Re}_{a}=9700$.

(vii) $\Delta P_{a}$ increases for $1.5 \mathrm{~mm} \leq \delta \leq 2.5 \mathrm{~mm}$ while $\Delta P_{a}$ decreases with $2.5 \mathrm{~mm}<\delta \leq 3.5 \mathrm{~mm}$ for the considered $\operatorname{Re}_{a}$ range except for $\operatorname{Re}_{a}=1850$, where there is no significant change of $\Delta P_{a}$ for $1.5 \mathrm{~mm} \leq \delta \leq$ $3.5 \mathrm{~mm}$.

(viii) Correlations for $P_{\mathrm{dc}}$ and $C_{f, m}$ based on the numerical results are obtained in terms of $\operatorname{Re}_{a}$ and $h_{f} / D_{\text {eq }}$.

The Resultant Point of View. The above-mentioned discussion showed that the wing-shaped tubes bundle heat exchanger with $h_{f}=6 \mathrm{~mm}$ has the lowest values of $\Delta P_{a}, P_{\mathrm{dc}}, C_{f}$, and $\mathrm{PP}$ and hence the best performance comparing with the other bundles. 


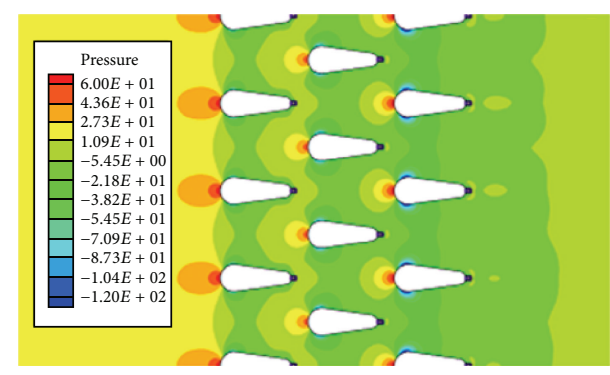

(a)

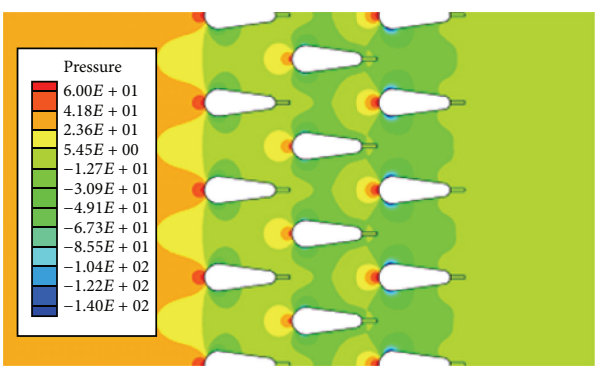

(c)

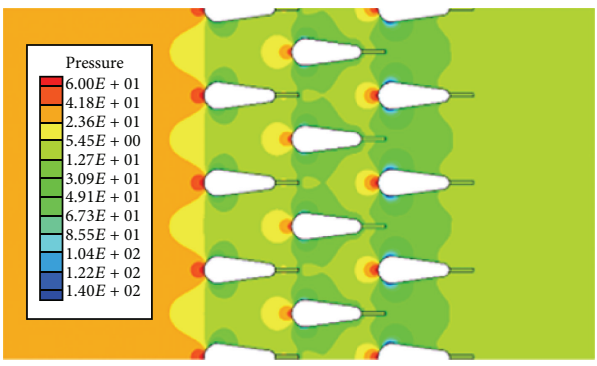

(e)

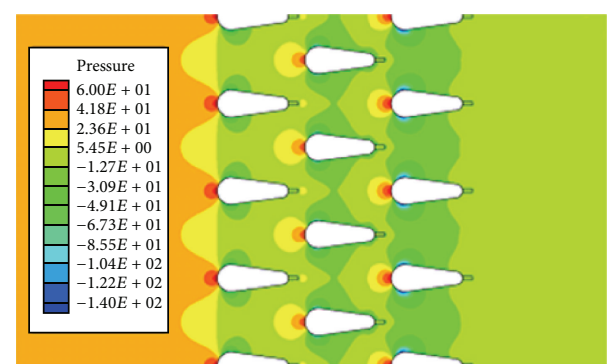

(b)

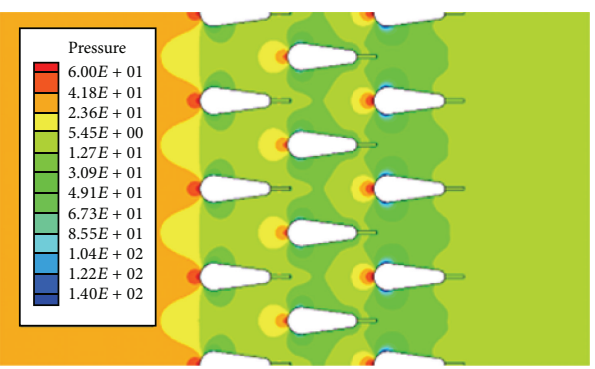

(d)

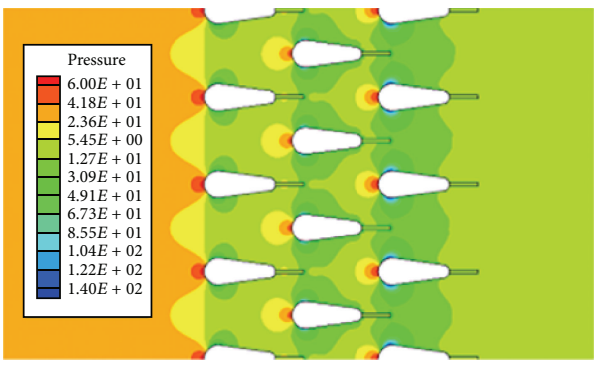

(f)

FiguRE 14: Static pressure contours (Pa) through the wing-shaped tubes bundle for different fin heights $\left(h_{f}\right)$ at $\operatorname{Re}=9700:(\mathrm{a}) h_{f}=2 \mathrm{~mm},(\mathrm{~b})$ $h_{f}=4 \mathrm{~mm},(\mathrm{c}) h_{f}=6 \mathrm{~mm},(\mathrm{~d}) h_{f}=8 \mathrm{~mm},(\mathrm{e}) h_{f}=10 \mathrm{~mm}$, and (f) $h_{f}=12 \mathrm{~mm}$.

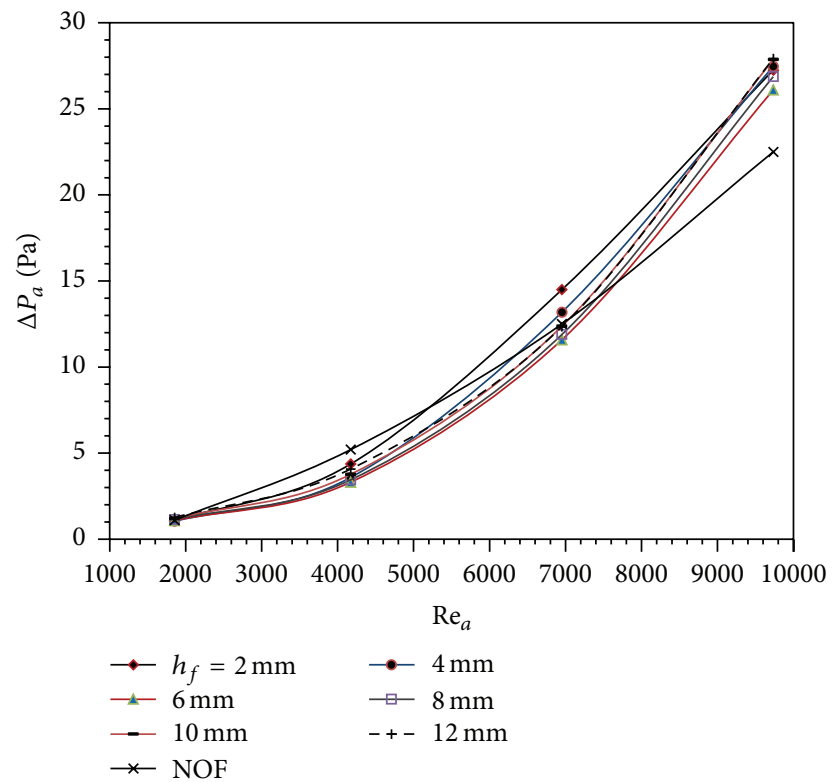

FIGURE 15: Variation of $\Delta P_{a}$ versus $\operatorname{Re}_{a}$ at different fin height.

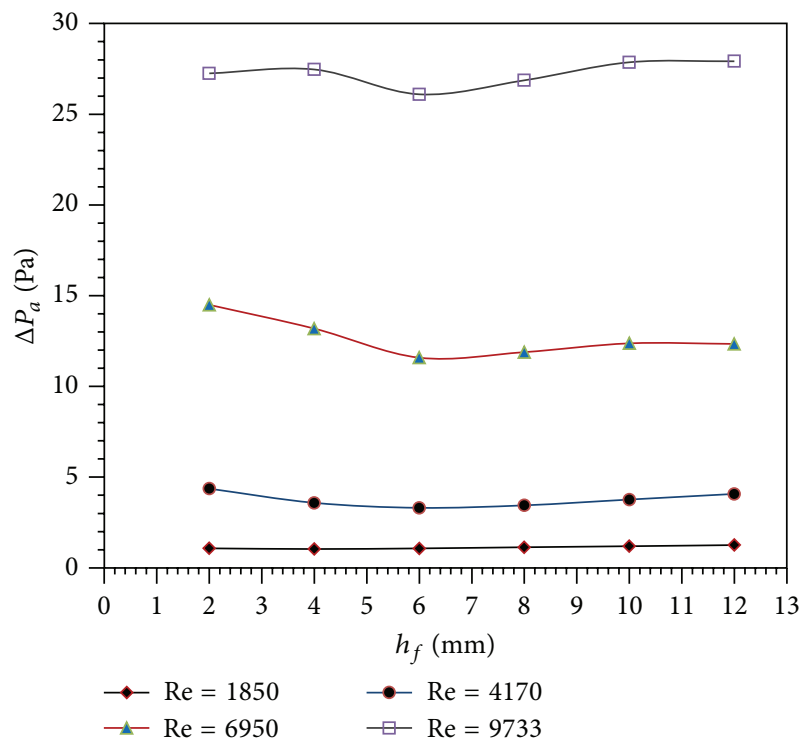

FIGURE 16: Variation of $\Delta P_{a}$ versus $h_{f}$ at different $\operatorname{Re}_{a}$. 


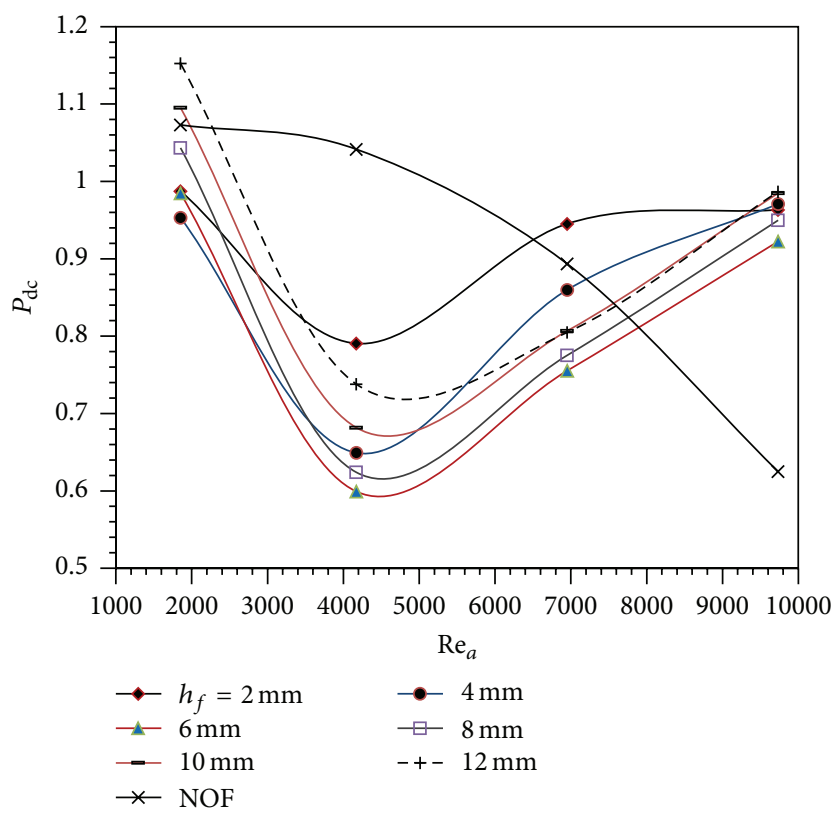

FIGURE 17: The effect of $\operatorname{Re}_{a}$ on $P_{\mathrm{dc}}$ for different $h_{f}$.

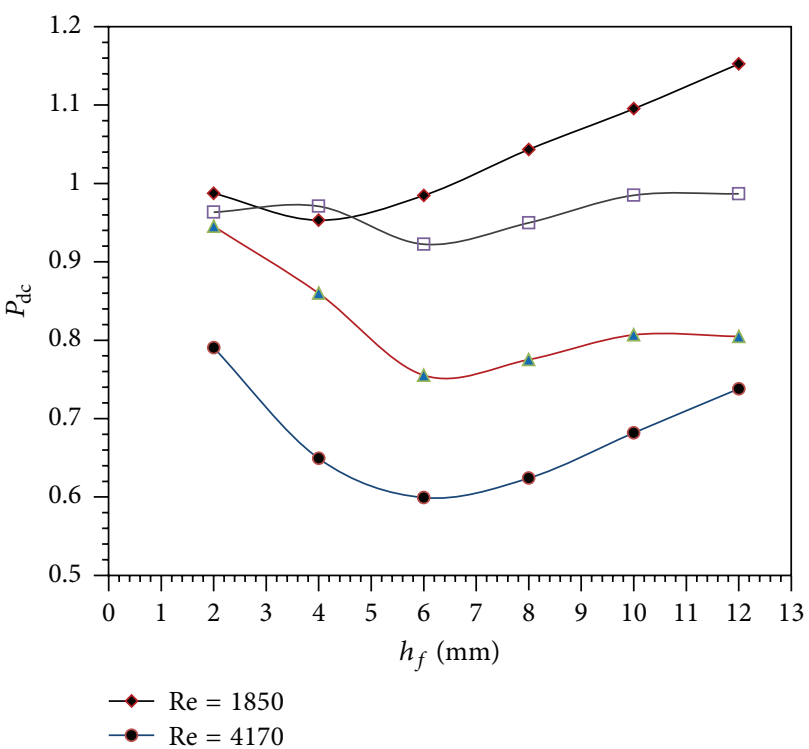

Figure 18: The effect of $h_{f}$ on $P_{\mathrm{dc}}$ for different $\mathrm{Re}_{a}$.

\section{Symbols}

\section{Alphabet: Upper Case}

PP: Pumping power, $\mathrm{W}$

$A_{\text {so }}$ : Total outer surface area of the tubes, $\mathrm{m}^{2}$

$D_{\text {eq }}$ : Equivalent circular diameter, $\mathrm{m}$

$F_{p}$ : Fin pitch, $\mathrm{m}$ (fin spacing + fin thickness)

$S: \quad$ Fin spacing, $\mathrm{m}$

$P_{\mathrm{dc}}$ : Pressure drop coefficient, $\left(2 \cdot \Delta P_{a}\right) /\left(\rho_{\mathrm{af}} \cdot V_{a}^{2}\right)$

$R^{2}$ : Coefficient of determination ranged from 0 to 1

Re: Reynolds number, $\left(\rho \cdot V \cdot D_{\text {eq }}\right) / \mu$

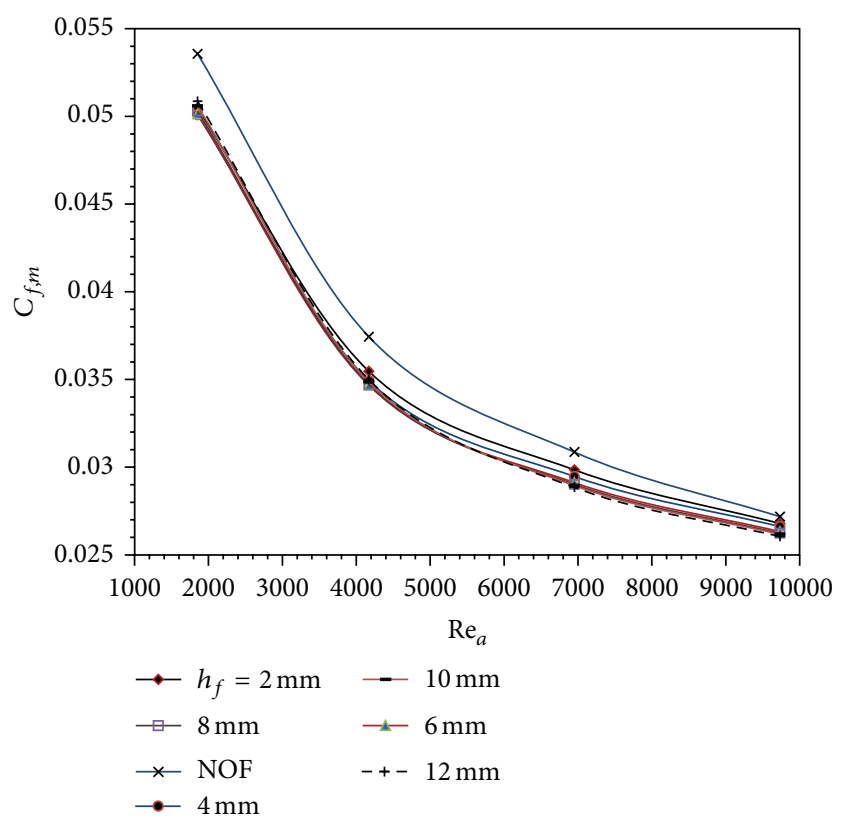

FIGURE 19: Variation of average skin friction coefficient $\left(C_{f, m}\right)$ versus $\operatorname{Re}_{a}$ at different $h_{f}$.

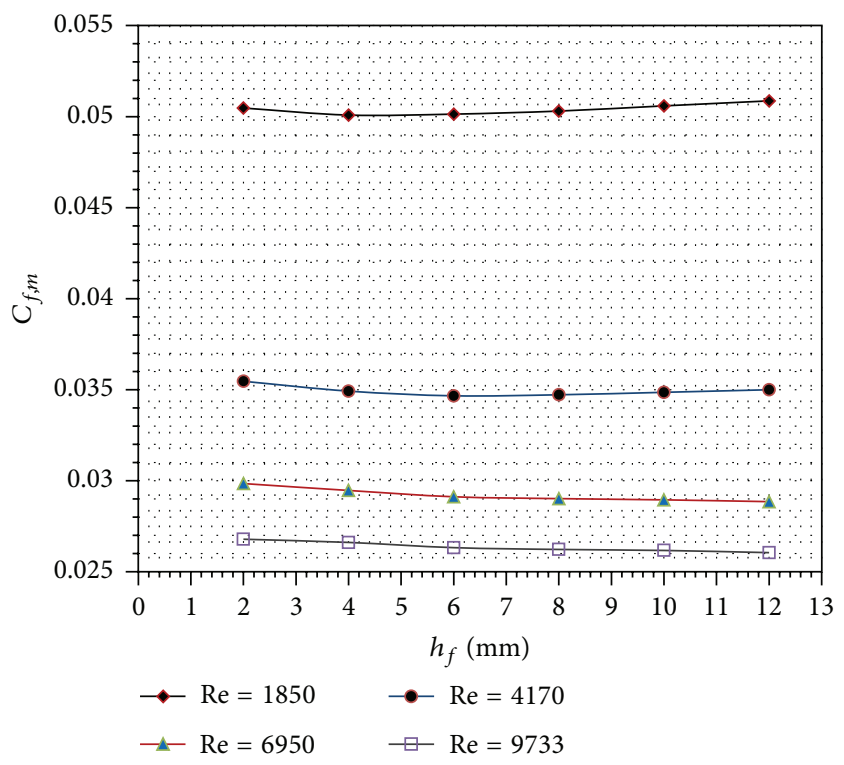

FigURE 20: Effect of $h_{f}$ on average skin friction coefficient $\left(C_{f, m}\right)$ at different $\operatorname{Re}_{a}$.

T: $\quad$ Temperature, $\mathrm{K}$

$V$ : Velocity, $\mathrm{m} / \mathrm{s}$

$S_{L}$ : Longitudinal tube pitch, $\mathrm{m}$

$S_{T}$ : Transverse tube pitch, $\mathrm{m}$

$S_{w}:$ Slit width, $\mathrm{m}$

$L_{l}$ : Louver length, $\mathrm{m}$

$L_{p}:$ Louver pitch, $\mathrm{m}$

$B$ : Surface emissivity parameter, dimensionless. 


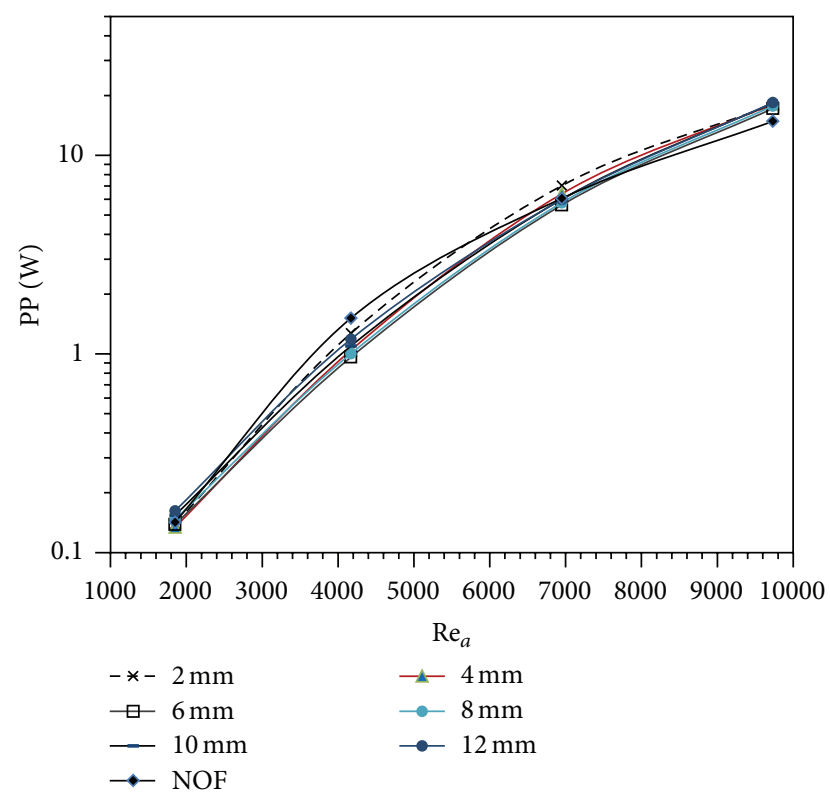

FIGURE 21: Effect of $\operatorname{Re}_{a}$ on pumping power (PP) for different $h_{f}$.

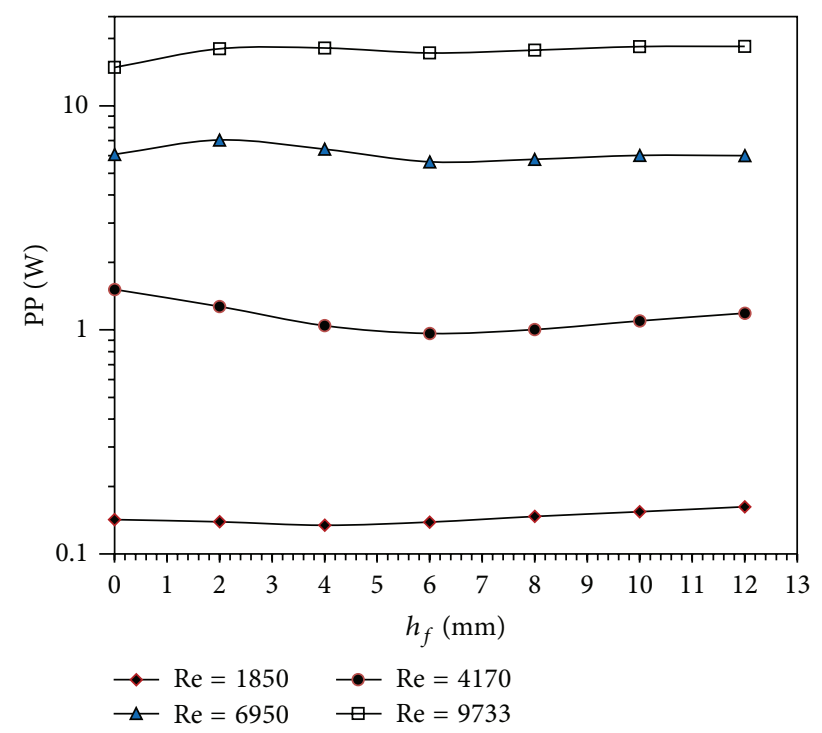

FIGURE 22: Effect of $h_{f}$ on pumping power (PP) at different $\mathrm{Re}_{a}$.

\section{Alphabet: Lower Case}

$c_{p}$ : Specific heat at constant pressure, $\mathrm{J} / \mathrm{kg} \cdot \mathrm{K}$

$h$ : Heat transfer coefficient, $\mathrm{W} / \mathrm{m}^{2} \cdot \mathrm{K}$

$k$ : Thermal conductivity, $\mathrm{W} / \mathrm{m} \cdot \mathrm{K}$

$m$ : Mass flow rate, $\mathrm{kg} / \mathrm{s}$

$t$ : Tube thickness, $\mathrm{m}$

$x$ : Axial coordinate

$y$ : The normal distance to the tube surface

$y^{+}$: Dimensionless normal distance to the tube surface

$h_{f}$ : Fin height, $\mathrm{m}$.

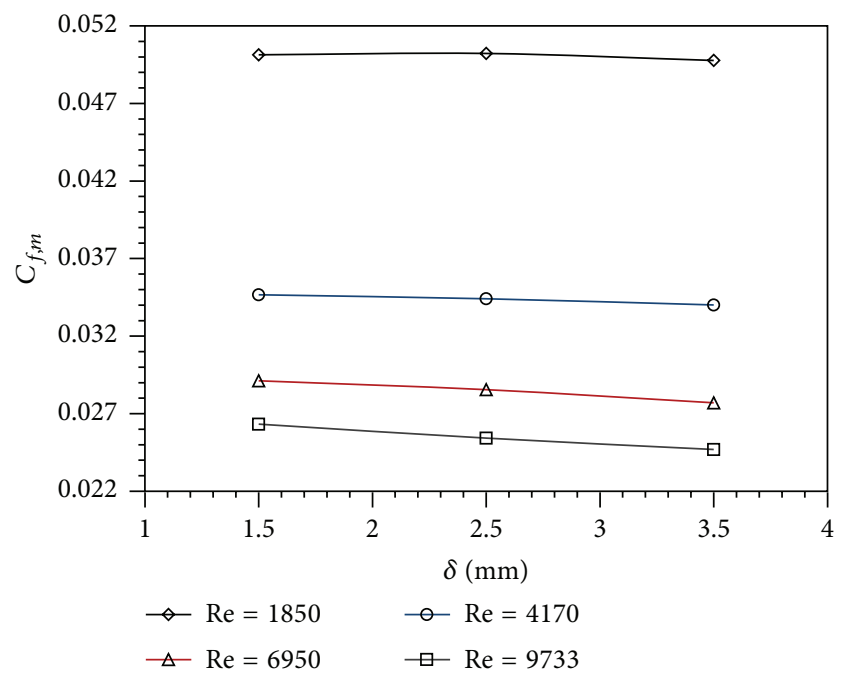

Figure 23: Effect of $\delta$ on $C_{f, m}$ for different $\mathrm{Re}_{a}$ at $h_{f}=6 \mathrm{~mm}$.

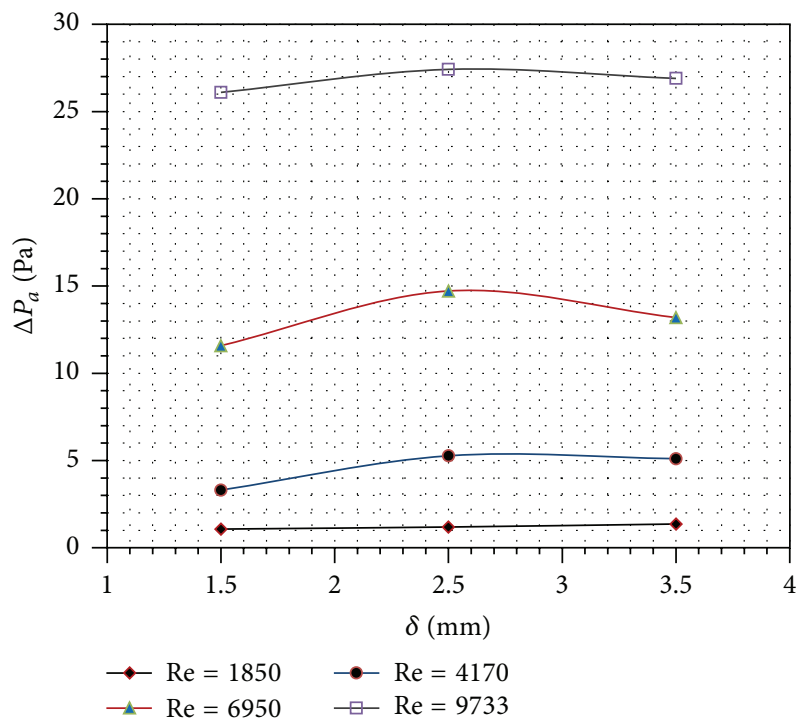

FIGURE 24: Effect of $\delta$ on $\Delta P_{a}$ for different $\operatorname{Re}_{a}$ at $h_{f}=6 \mathrm{~mm}$.

\section{Greek Symbols}

$\mu$ : $\quad$ Absolute viscosity, Pa.s

$\theta: \quad$ Louver angle, 。

$\rho: \quad$ Density, $\mathrm{kg} / \mathrm{m}^{3}$

$\Delta P_{a}$ : Pressure drop across the bundle, $\mathrm{Pa}$

$\Phi: \quad$ Irreversibility ratio

$\eta_{f}:$ Fin efficiency

$\delta: \quad$ Fin thickness, $m$.

\section{Subscripts}

a: Air

c: Circular

$e$ : Exit

$f$ : Film or fin 
$i$ : Inlet or row number

$o$ : Outer or outlet

$h$ : Height

L: Longitudinal.

\section{Abbreviations}

RNG: Reynolds normalized group

LFTH: Longitudinal finned tubes heat exchanger

NOF: Without fin

DTM: Differential transformation method.

\section{Conflict of Interests}

The authors declare that there is no conflict of interests regarding the publication of this paper.

\section{References}

[1] H.-T. Chen, J.-C. Chou, and H.-C. Wang, "Estimation of heat transfer coefficient on the vertical plate fin of finnedtube heat exchangers for various air speeds and fin spacings," International Journal of Heat and Mass Transfer, vol. 50, no. 1-2, pp. 45-57, 2007.

[2] J.-Y. Jang, M.-C. Wu, and W.-J. Chang, "Numerical and experimental studies of three-dimensional plate-fin and tube heat exchangers," International Journal of Heat and Mass Transfer, vol. 39, no. 14, pp. 3057-3066, 1996.

[3] C.-C. Wang, Y.-J. Chang, Y.-C. Hsieh, and Y.-T. Lin, "Sensible heat and friction characteristics of plate fin-and-tube heat exchangers having plane fins," International Journal of Refrigeration, vol. 19, no. 4, pp. 223-230, 1996.

[4] A. F. Khudheyer and M. S. Mahmoud, "Numerical analysis of fin-tube plate heat exchanger by using CFD technique," Journal of Engineering and Applied Sciences, vol. 6, no. 7, pp. 1-12, 2011.

[5] M. V. Ghori and R. K. Kirar, "Numerical analysis of tube-fin heat exchanger using fluent," International Journal on Theoretical and Applied Research in Mechanical Engineering, vol. 1, no. 2, pp. 3744, 2012.

[6] W.-M. Yan and P.-J. Sheen, "Heat transfer and friction characteristics of fin-and-tube heat exchangers," International Journal of Heat and Mass Transfer, vol. 43, no. 9, pp. 1651-1659, 2000.

[7] I. Wolf, B. Frankovic, I. Vilicic, R. Jurkowski, and A. Bailly, "A numerical and experimental analysis of heat transfer in a wavy fin and tube heat exchanger," in Energy and the Environment, pp. 91-101, 2006.

[8] L. H. Tang, M. Zeng, and Q. W. Wang, "Experimental and numerical investigation on air-side performance of fin-andtube heat exchangers with various fin patterns," Experimental Thermal and Fluid Science, vol. 33, no. 5, pp. 818-827, 2009.

[9] J.-S. Leu, M.-S. Liu, J.-S. Liaw, and C.-C. Wang, "A numerical investigation of louvered fin-and-tube heat exchangers having circular and oval tube configurations," International Journal of Heat and Mass Transfer, vol. 44, no. 22, pp. 4235-4243, 2001.

[10] C. T'Joen, H. Huisseune, H. Canire, H. J. Steeman, A. Willockx, and M. De Paepe, "Interaction between mean flow and thermohydraulic behaviour in inclined louvered fins," International Journal of Heat and Mass Transfer, vol. 54, no. 4, pp. 826-837, 2011.

[11] W. Li and X. Wang, "Heat transfer and pressure drop correlations for compact heat exchangers with multi-region louver fins," International Journal of Heat and Mass Transfer, vol. 53, no. 15-16, pp. 2955-2962, 2010.

[12] E. M. Sparrow and S. S. Kang, "Longitudinally-finned crossflow tube banks and their heat transfer and pressure drop characteristics," International Journal of Heat and Mass Transfer, vol. 28, no. 2, pp. 339-350, 1985.

[13] E. Ibrahim and M. Moawed, "Forced convection and entropy generation from elliptic tubes with longitudinal fins," Energy Conversion and Management, vol. 50, no. 8, pp. 1946-1954, 2009.

[14] M. Torabi and Q. B. Zhang, "Analytical solution for evaluating the thermal performance and efficiency of convective-radiative straight fins with various profiles and considering all nonlinearities," Energy Conversion and Management, vol. 66, pp. 199-210, 2013.

[15] Z. Hu and D.-W. Sun, "Predicting local surface heat transfer coefficients by different turbulent $\mathrm{k}-\varepsilon$ models to simulate heat and moisture transfer during air-blast chilling," International Journal of Refrigeration, vol. 24, no. 7, pp. 702-717, 2001.

[16] V. Yakhot, S. A. Orszag, S. Thangam, T. B. Gatski, and C. G. Speziale, "Development of turbulence models for shear flows by a double expansion technique," Physics of Fluids A, vol. 4, no. 7, pp. 1510-1520, 1992.

[17] FLUENT 6.3.26 User's Guide, FLUENT Inc, 2006.

[18] E. S. Sayed Ahmed, E. Z. Ibrahiem, O. M. Mesalhy, and M. A. Abdelatief, "Effect of attack and cone angels on air flow characteristics for staggered wing shaped tubes bundle," Heat and Mass Transfer, vol. 51, no. 7, pp. 1001-1016, 2015.

[19] S. A. E. Sayed Ahmed, E. Z. Ibrahiem, O. M. Mesalhy, and M. A. Abdelatief, "Heat transfer characteristics of staggered wingshaped tubes bundle at different angles of attack," Heat and Mass Transfer, vol. 50, no. 8, pp. 1091-1102, 2014. 

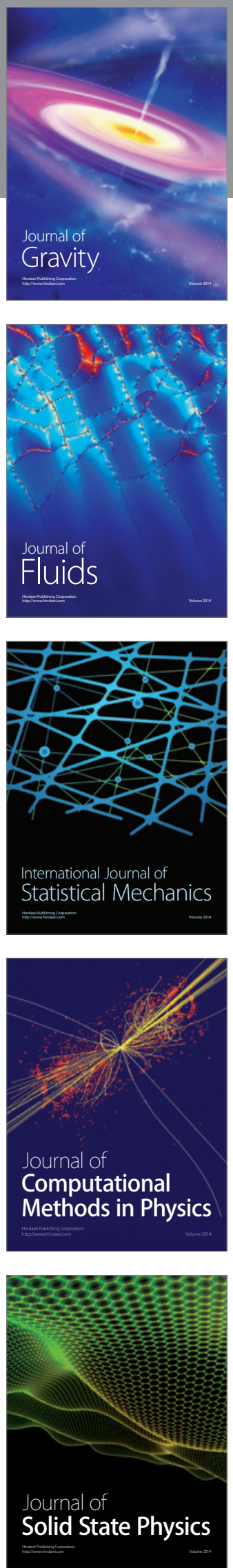

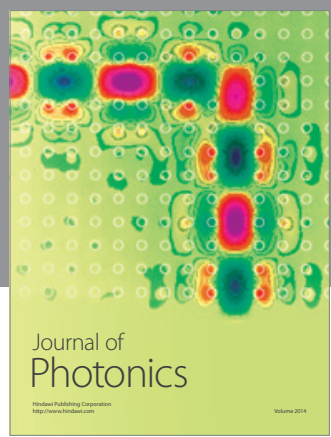

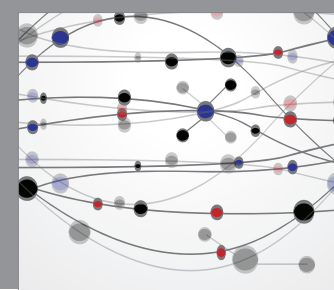

The Scientific World Journal

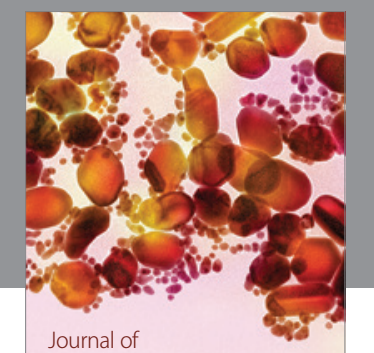

Soft Matter
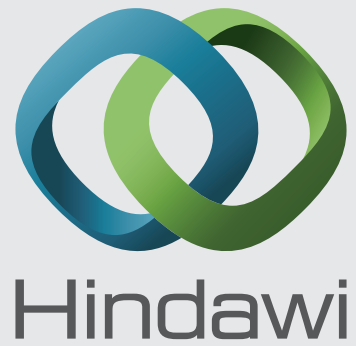

Submit your manuscripts at

http://www.hindawi.com
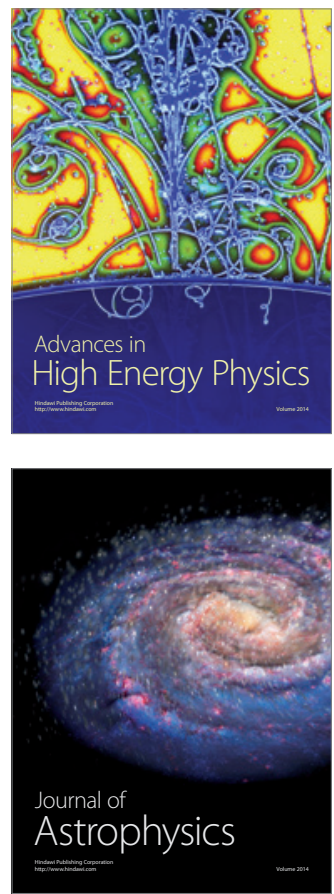
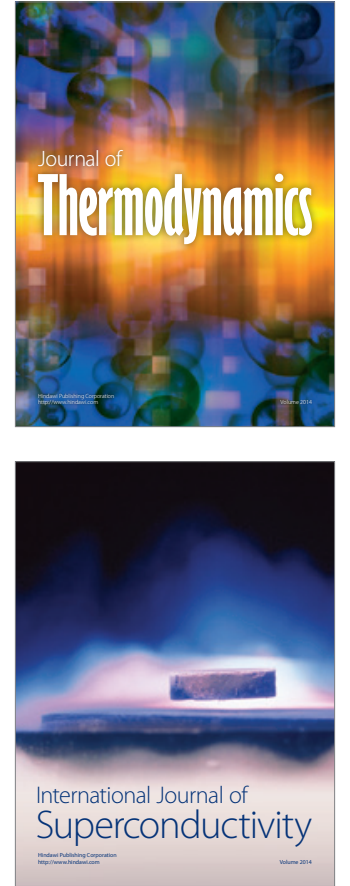
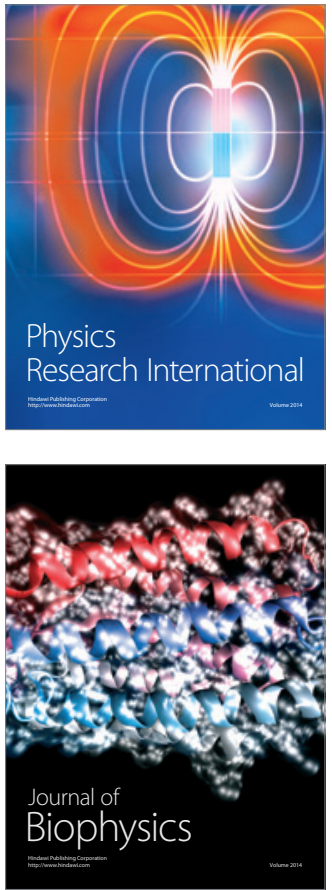
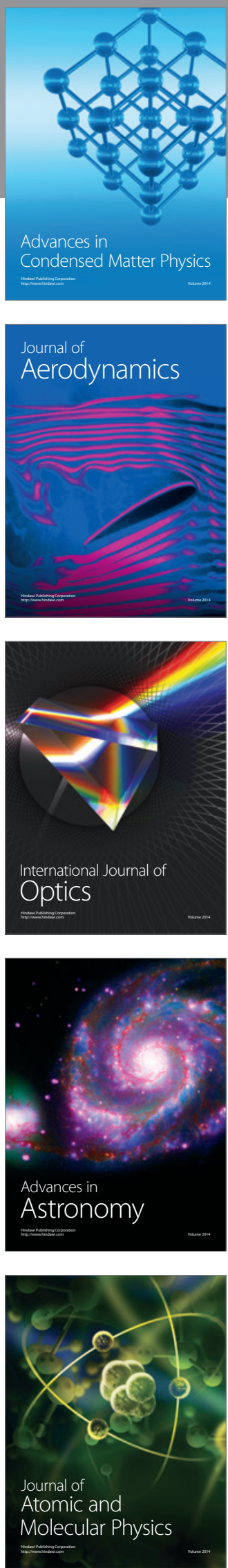